\title{
Directly Attached Acetylacetone to Polyurethane Foam as Solid-Phase Extractor for Determination of Metal Ions in Natural Samples
}

\author{
Sami M. Abdel Azeem ${ }^{\mathrm{a}}$, Salma M. Moftah ${ }^{\mathrm{b}}$ and Mohamed F. El-Shahat ${ }^{\mathrm{b}^{*}}$ \\ ${ }^{a}$ Chemistry Department, Faculty of Science, Fayoum University, Egypt \\ ${ }^{b}$ Chemistry Department, Faculty of Science, Ain-Shams University, Egypt
}

\section{A R T I C L E I N F O}

Article history:

Received 08 July 2012

Accepted 12 August 2012

Keywords:

Acetylacetone;

Polyurethane foam;

Solid-phase extraction.

\begin{abstract}
A B S T R A C T
Acetylacetone (AA) was chemically anchored to polyurethane foam (PUF) via azo coupling of the toluidine $-\mathrm{NH}_{2}$ in PUF and active $-\mathrm{CH}_{2}$ - in AA. The sorbent was used for off-line solid-phase extraction (SPE) and flame atomic absorption (FAAS) determination of $\mathrm{Cu}(\mathrm{II}), \mathrm{Zn}$ (II) and $\mathrm{Mn}$ (II) in natural samples. The AA-PUF sorbent was characterized by UV-VIS, IR, $\mathrm{H}^{1}$ NMR, elemental and TGA analysis. Optimal experimental conditions were at $\mathrm{pH}$ 6, shaking time of 20 min, sample flow rate of $1.0 \mathrm{ml} \mathrm{min}^{-1}$, and desorption by $10 \mathrm{~mL}$ from $0.4 \mathrm{~mol} \mathrm{~L}^{-1}$ hydrochloric acid. Limits of detection (LOD) were $0.14,0.51$ and $0.14 \mu \mathrm{g} \mathrm{L}^{-1}$ and precision (RSD \%) were 6.3, 5.3 and 3.2\% $(\mathrm{n}=5)$, respectively. All metal ions showed an analytical range of $0.3-20 \mu \mathrm{g} \mathrm{L}^{-1}$ and preconcentration factor of 100 . The proposed method has been successfully applied to the determination of these metal ions in real samples (tap water, olive leaves, and fish liver) with recovery of $91.26 \% \mathrm{Cu}, 84.00 \% \mathrm{Zn}$ and $87.34 \% \mathrm{Mn}$ and corresponding RSD values less than $10 \%$.
\end{abstract}

\section{Introduction}

In recent years, trace heavy metal contamination has been a serious problem for environment in the areas with intensive industry ${ }^{[1]}$. Wastewater from non-ferrous metal ore mining and smelting, electroplating and other industrial production process, is an important pollution source of heavy metal ${ }^{[2]}$. Mining activities generate a large amount of tailings that are generally deposited upon the soil surface. Tailings usually provide an unfavorable substrate for plant growth because of their low $\mathrm{pH}$, high concentrations of trace elements and low nutrient content ${ }^{[3]}$. Trace element contamination may originate from both natural geochemical processes (weathering of ultramafic rocks) and anthropogenic activities (such as mining and smelting, combustion of fossil fuels, utilization of fertilizers and pesticides, disposal of wastes) ${ }^{[4]}$. Heavy metals are involved in various industrial processes, agricultural activities, domesticwastes, and vehicles emission, and they are considered as one of the most serious pollutants due to their persistence in the environment, bioaccumulation and high toxicity ${ }^{[5]}$.

* Corresponding author.

E-mail address: salmaa172000@yahoo.com
Sediments are ecologically important components of the aquatic habitat and are also a reservoir of contaminants, which play a significant role in maintaining the trophic status of any water body. The measurements of pollutants in the water only are not conclusive due to water discharge fluctuations and low resident time. The same holds true for the suspended material ${ }^{[6]}$. Heavy metals can be readily transferred into the human body as a consequence of dermal contact absorption, inhalation, and ingestion and then the metal can typically accumulate in human body due to their non-biodegradable nature and long biological half-lives for elimination. It has been found that heavy metals in urban soils may have toxic effects on human health ${ }^{[7]}$. Trace amounts of heavy metals are always present in water, and some elements may be involved in absorption, co-precipitation, complex formation, and co-adsorbed with other particulate forms ${ }^{[8]}$. Due to waste residue, waste water and exhaust gas from industry and traffic etc [9]. The trace and toxic metals are generally present in trace concentrations in environmental samples, for example copper is essential for human beings in trace quantity ${ }^{[10]}$. Adverse effect is manifested when these levels exceed a threshold level; higher level of essential 
trace metals in our body is creating health risk. Due to these reasons, the accurate and precise determination of trace metal ions important for analytical chemists ${ }^{[11]}$.

Levels of metals in fish are of considerable interest because of potential effects on the fish themselves or the organisms that consume them, including top-level receptors, including people ${ }^{[\mathbf{1 2}]}$.

The concentration of trace elements can be high in plant species growing in contaminated soils, not only in the leaves but also in the branches, and may pose severe risks to the health of the population on occasions ${ }^{[13]}$. The use of instrumental methods for trace metal quantifi-cation frequently requires preconcentration procedures to lower the detection limits. Methods widely used for preconcentration usually involve an ion-exchange or liquid-liquid extraction separation. Chelating ion-exchange resins are capable of preconcentrating metal ions selectively from a large aqueous volume and may easily be coupled with flame atomic absorption spectrometry (FAAS) to enhance its sensitivity. A chelating resin-based on-line preconcentration and matrix separation of metal ions followed by their determination with FAAS and inductively coupled plasma-mass spectrometry have also been employed ${ }^{[14]}$.

Various analytical techniques have been used such as atomic absorption spectroscopy (AAS), ICP and plasma emission spectroscopy (ES/MS) ${ }^{[15]}$. In trace element analysis, preconcentration and separation step is needed to enhance the sensitivity and precision of the determination. The presence of trace heavy metals lower than the detection limits of instrumental techniques is one of the main lat levels. Therefore, preconcentration techniques including liquid-liquid extraction ${ }^{[16]}$, cloud point extraction ${ }^{[17]}$, electrode position, coprecipitation, and solid phase extraction are generally used by the researchers around the world ${ }^{[10,18]}$. Preconcentration techniques such as adsorption, solid-phase extraction (SPE) membrane filtration [19], and different filtration materials have been used so far: nylon ${ }^{[20]}$, glass fibre filters [21], cellulose [22], solvent extraction and coprecipitation have been carried out ${ }^{[23]}$.

Solid Phase Extraction (SPE) is an attractive technique based on the use of sorbent that retains the analytes ${ }^{[24]}$, is preferentially used, mainly due to its simplicity, low cost, contaminant free and adaptation to flow injection techniques ${ }^{[10]}$. The advantages of the column SPE over liquid-liquid extraction are the higher concentration factor. SPE is an ideal technique for trace metals separation/preconcentration, and it possesses virtues such as simplicity, flexibility, easy of automation, and high enrichment factor. Since the adsorption materials play a very important role in SPE, much of the current research in SPE focuses on the development of new sorbents. To date, many novel adsorbents, such as nano materials, ion imprinted material, mesoporous materials, carbon nano tubes and magnetic nanoparticles have been employed in SPE ${ }^{[25]}$.
Before analysis, due to the complexity of some sample matrices, their incompatibility with the desired instrumental method and low concentrations of the analytes in water, a preliminary sample preconcentration and/or separation technique is required. Solid-phase extraction (SPE) ${ }^{[26]}$, in many causes analytical techniques are not sufficient for trace determination and a separation/preconcentration step prior to determination by FAAS is required. It is one of the most used techniques for samples pretreatments for complex matrices, mainly because trace analyte preconcentration and sample matrix removal are achieved at time ${ }^{[27]}$.

Preconcentration procedures are therefore necessary to improve the sensitivity and selectivity in trace-metal determination ${ }^{[28]}$. Inductively coupled plasma-mass spectrometry (ICP-MS) techniques are costly and they still suffer from matrix effects when samples are analyzed directly. Therefore, a sample pretreatment step, which can separate the analytes from the matrix components and preconcentrate them before their measurement, is often mandatory ${ }^{[25]}$. The treated of polyurethane foam by (PUF) hydrolysis with hydrochloric acid, to form a diazonium salt, which couples with $\alpha$-naphthylamine, $\alpha$-naphthol, $\beta$-naphthol, 8-hydroxyquinoline, resorcinol, or catechol. Introduction of primary amine group on polyurethane foam is also tried via a nitration step followed by reduction of nitro groups with zinc dust in acid media. The purple azo dye formed on the surface of the foam material is used for quantitative and/or semiquantitative determination of submicrogram amounts of nitrite ${ }^{[29]}$.

Sorbents have been successfully used for the preconcentration; separation and sensitive determination of trace metal ions, such as; Polyurethane Foam (PUF) is material in which a proportion of solid phase is replaced by numerous small bubbles (cells) ${ }^{[30]}$. PUF is merited by its very low cost and simplicity of preparation. Moreover, this material is resistant to $\mathrm{pH}$ changes, and has a reliable resistance to swelling when placed in organic solvents. The action of sodium nitrite $\left(\mathrm{NaNO}_{2}\right)$ on the thermal amine groups of PUF in present of 0.1 $\mathrm{MHCl}$ leads to a yellow color on the foam, which is attributed to the diazotization reactions and the formation of the diazonium chloride in the foam ${ }^{[31]}$.

A polyether type polyurethane foam loaded with TAC (2-(2-thiazolylazo)-p-cresol) for determination of cobalt in water samples ${ }^{[32]}$, polystyrene functionalized with N,N-bis(naphthylideneimino)diethylenetriamine

(NAPdein) for determination of trace levels of cadmium(II) by FAAS ${ }^{[33]}$.

PUF loaded with 2-(2-benzothiazolylazo)-2-p-cresol (BTAC) reagent. An on-line system for enrichment and determination of lead ${ }^{[34]}$. Many reagents have been in immobile on PUF such as 2-Aminoacetylthiophenol modified polyurethane foam was successfully synthesized by coupling the foam through 2-aminoacetylthiophenol ${ }^{[35]}$. 
The PUF functional groups are highly reactive towards diazotization by sodium nitrite, azo coupling with 4-nitrophenyldiazonium tetrafluoroborate, oxidation by active chlorine, and condensation with formaldehyde, resulting in the formation of intensely colored products [36]. PUF functionalized with a-naphthol was synthesis by covalently linking them through an $-\mathrm{N}=\mathrm{N}-$ group. The characterization of 1-naphthol bonded to polyurethane foam (1-Nap-PUF) ${ }^{\text {[3] }}$ a method for the incorporation of Nile blue A into polyurethane foam matrix ${ }^{[18]}$, the grafted polyurethane foam sorbents were prepared by coupling polyether polyol, toluene di isocyanate and basic dyestuff (Methylene blue, Rhodamine $\mathrm{B}$ and Brilliant green). The Me.B-PUF, Rh.B-PUF and Br.G-PUF ${ }^{[38]}$. Penicillins (penicillin G, amoxicillin, and ampicillin) are extracted in a mincolumn packed with methylene blue grafted polyurethane foam (MBGPUF) material [30], o-Aminophenol (AP) and its azo derivative with ß-Naphthol(Naph) is bonded to PUF (BPUF) and used as solid phase extractor of $\mathrm{Ni}, \mathrm{Cd}$ and $\mathrm{Zn}$ ions ${ }^{[39]}$. The simplicity of operation and flexibility of working conditions of SPE are dependent on the proper choice of sorbent material. Different sorbents have been used for solid phase extraction of zinc including polyurethane foam ${ }^{[27]}$.

Acetylacetone forms chemical modification of PUF was done to terminal- $\mathrm{NH}_{2}$ via azo compiling with Acetylacetone phenyl hydrazone condensation with $\mathrm{HCl} / \mathrm{NaNO}_{3}{ }^{[40]}$. Versatile and useful chelate compounds with various kinds of metals. For example the complexes of $\mathrm{Mn}(\mathrm{II}), \mathrm{Co}(\mathrm{II}), \mathrm{Ni}(\mathrm{II}), \mathrm{Cu}(\mathrm{II})$ and $\mathrm{Zn}$ (II) with a novel heterocyclic azo derivative formed by coupling diazotized 2-amino-3-carbethoxy4,5-dimethylthiophene with acetylacetone [41], and therefore its structure and reactivity have been important issues in many fields of science. Acetylacetone has two interesting structural isomers, diketo and enol, and it is well known from spectroscopic evidences that the relative population of these two varies depending on the characteristics of environment ${ }^{[42]}$. In its enolic form has been found to produce the $\mathrm{OH}$ radical as a phtofragment after the $\pi-\pi^{*}$ transition induced by UV irradiation ${ }^{[43]}$. Condensation product between acetyl acetone and primary amines is hydrazone compound with the formula $-\mathrm{R}_{2} \mathrm{C}=\mathrm{NR}-$ and these ligands are well known to form stable complexes of metals ${ }^{[44]}$.

In this work, the terminal amine group in the untreated PUF was utilized for the azo dye formation. By coupling the diazotized PUF with the active methylene group of acetylacetone. The synthesized sorbent containing azo groups adjacent to hydroxyl groups to yield chelating sites for the complication to metal ions.

\section{Experimental}

\subsection{Instrumentations}

The UV-Visible spectrophotometer model UV-1601 (Shimadzu, Japan) was used to record the absorption spectra of the new sorbent. Unicam flame atomic absor- ption spectrometer (FAAS) model SOLAAR32Help@969 (England), was used for details metals ion HC lamp current and wavelength for determination of copper (10mA, 213.9nm), $\mathrm{Zn}(5 \mathrm{~mA}$, $324.8 \mathrm{~nm})$ and $\mathrm{Mn}(12 \mathrm{~mA}, 279.5 \mathrm{~nm})$. The calibration lines were $\mathrm{A}=0.084 \mathrm{C}+0.0055 \quad(\mathrm{R}=0.99991)$, $\mathrm{A}=0.162 \mathrm{C}+0.02 \quad(\mathrm{R}=0.99795)$, and $\mathrm{A}=0.053 \mathrm{C}+0.0078$ $(\mathrm{R}=0.99998)$, respectively. The $\mathrm{pH}$ measurements were carried out on a WTW720 pH meter model CT16 2AA (LTD Dover Kent, UK) and equipped with a combined glass electrode. Wrist Action shaker mechanical shaker was purchased from Burrel, model El75 (PA, U.S.A). Elemental analysis CHNS was done by elemental analyses system GmbH, model vario ELIII (Hanau, Germany). NMR spectra were recorded on mercury-300bb "NMR300" spectrometer (Varian300, USA) and dimethylsulfoxide (DMSO) was used as solvent. Thermo scientific Nicolet FT-IR model 6700 (Illinois, USA) was used to record the infrared spectra in the range 400- $4000 \mathrm{~cm}^{-1}$. The thermogravimetric analysis was performed on shimadzu TGA analyzer model TGA-50H (Rash, Japan) at rate flow 30.00 (mL $\mathrm{min}^{-1}$ ) and holding temperature 500, in a controlled atmosphere. The initial weight of each sample was around 1.173-2.225 mg. The samples were kept in a platinum crucible and heated in the furnace, flushed with $\mathrm{N}_{2}$ gas at the rate of $30 \mathrm{~mL} \mathrm{~min}^{-1}$, from 25 to $700^{\circ} \mathrm{C}$, at the rate of $10^{\circ} \mathrm{C} \mathrm{min}$.

\subsection{Reagents}

Unless otherwise stated, all reagents were of analytical-reagent grade. Distilled water was used to prepare the solutions. Laboratory glassware was soaked in $18 \mathrm{~mol} \mathrm{~L}^{-1}$ sulfuric acid solutions then washing by distilled water and dried in dust free environment. Acetylacetone and phenylhydrazine were obtained from sigma-Aldrich (USA) and Prolabo, Rue palee, (Paris, France), respectively. Mineral acids including nitric, sulfuric and hydrochloric were obtained from Merck (Darmstadt, Germany). Standard solutions metal ion (1000 mg L $\mathrm{L}^{-1}$ ) were prepared by dissolving 3.9291g, $2.7443 \mathrm{~g}$, and $4.0832 \mathrm{~g}$ of dried $\mathrm{CuSO}_{4} .5 \mathrm{H}_{2} \mathrm{O}$ (adwic, El-Nasr, Egypt), $\mathrm{ZnSO}_{4}$ (merck), and $\mathrm{MnSO}_{4} \cdot 4 \mathrm{H}_{2} \mathrm{O}$ (adwic), respectively. A $1 \mathrm{~L}$ solution containing $1 \mathrm{~mL}$ concentrated nitric acid. Working solution $10 \mu \mathrm{g} \mathrm{mL}$ was prepared within-day work by dilution from the standards, by distilled water. Commercial PUF, open-cell polyether type, was supplied from the Egyptian Company for Foam Production (Cairo, Egypt). The PUF was cut into similar cubes (50 $\mathrm{mm}$ dimension), washed by $0.1 \mathrm{~mol} \mathrm{~L}^{-1}$ solution of $\mathrm{HCl}$, followed by distilled water and ethanol and then squeezed between clean sheets of filter paper and dried in a stove at $80^{\circ} \mathrm{C}$ for 1.0 $\mathrm{h}$ and stored in a dark bottle.

\subsection{Synthesis of AA-PUF}

The diazotized PUF was coupled to acetylacetone to get the azo product. For this purpose, one-gram PUF cubes was soaked in $\mathrm{HCl}(50 \% \mathrm{w} / \mathrm{v})$ for $6 \mathrm{~h}$ to liberate the maximum number of free $\mathrm{NH}_{2}$ groups by the hydrolysis of residual isocyanate and some urethane groups. 
Thereafter, the foam was washed with water, placed into a $0.1 \mathrm{~mol} \mathrm{~L}^{-1} \mathrm{HCl}$ solution $(100 \mathrm{~mL})$ and cooled in an ice bath. Diazotization was affected by the drop wise addition of $1 \mathrm{~mol} \mathrm{~L}^{-1}$ solution of sodium nitrite to the cold mixture, and stirred vigorously until the yellow color appeared in PUF due to the formation of diazonium salt. The mixture was thermostated for $1 \mathrm{~h}$ at a temperature below $3^{\circ} \mathrm{C}$. After that, the plugs were transferred to a mixture containing of $5 \mathrm{ml}$ (AA), $1 \mathrm{~mol}$ $\mathrm{L}^{-1}$ sodium acetate in $50 \%(\mathrm{w} / \mathrm{v})$ ethanol and stirred. A canary yellow plug from AA-PUF were obtained and kept in an ice for $24 \mathrm{~h}$. Finally, the yellow plugs were

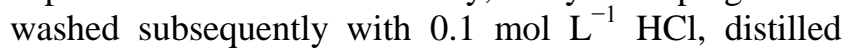
water and ethanol then dried.

\subsection{General procedure \\ Batch procedure}

Solutions containing $\mathrm{Cu}(\mathrm{II}), \mathrm{Zn}$ (II) and $\mathrm{Mn}$ (II) at concentration $0.5 \mu \mathrm{g} \mathrm{mL}^{-1}$ each metal ion. The influence of extraction time on sorption capacity was investigated at various shaking periods $(5,10,15,20,25$ and $30 \mathrm{~min})$ at the selected $\mathrm{pH}$ of maximum extraction. Also, the maximum capacity of AA-PUF for was determined under "static" batch conditions. A $20 \mathrm{~mL}$ solution containing $0.5 \mu \mathrm{g} \mathrm{mL}{ }^{-1}$ each element was shaken with $100 \mathrm{mg}$ AA-PUF for $1.0 \mathrm{~h}$ after adjusting the sample to optimized $\mathrm{pH}$.

\subsection{Column preparation}

A glass column, $20 \mathrm{~cm}$ long and $1 \mathrm{~cm}$ internal diameter, having a stopcock was used. Small glass beads were put above the stopcock to serve as the base for the foam plugs. Then, $1.0 \mathrm{~g}$ of AA-PUF sorbent was packed inside the column by applying gentle pressure with a glass rod. The foam is about $2 \mathrm{~cm}$ bed height. All the times the foam was immersed in solution to avoid bubbles or channel formation. It was washed with 0.1 mol L ${ }^{-1} \mathrm{HCl}$ solution and cleaning with distillation water, conditioned to the desired $\mathrm{pH}$ before running the experiments. At end day work, the column was washed with large volumes of distilled water and stored filled with water for the next preconcentration cycle. A sample solution containing $0.5 \mu \mathrm{g} \mathrm{mL}^{-1}$ metal ion in a volume of $20 \mathrm{~mL}$ was taken and its $\mathrm{pH}$ was adjusted to optimum $\mathrm{pH}$ for maximum extraction. Influence of solution flow rate, eluent concentration and volume, sample volume and interfering ions were examined. The foam sorbent was activated for each run by washing with $5 \mathrm{ml}$ of

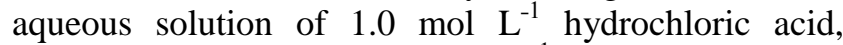
treating with $5 \mathrm{ml}$ of $0.1 \mathrm{~mol} \mathrm{~L}^{-1}$ sodium hydroxide solution, and finally washing with $20 \mathrm{ml}$ of distilled water to remove all hydroxide and the effluent become neutral.

\subsection{Sample preparation}

\subsubsection{Olive leaves}

Olive leaves were obtained from a local market in Cairo City. The green leaves were washed many times with distilled water to remove any dust and cut into small pieces then dried in an oven at $80^{\circ} \mathrm{C}$ for $10 \mathrm{~h}$ till constant weight. After that, the dried leaves were ground in porcelain mortar. Digestion of the dry sample was effec- ted by accurately weighing $0.50 \mathrm{~g}$ from the powdered sample and thoroughly mixed with $20 \mathrm{~mL}$ of $14 \mathrm{~mol} \mathrm{~L}^{-1}$ concentrated nitric acid solution in a clean glass beaker. The mixture was heated on hotplate within fume cupboard till nearly dryness. After cooling, distilled water was added to the final digest and it was neutralized to $\mathrm{pH} 7$ using $2.5 \mathrm{~mol} \mathrm{~L}^{-1}$ sodium hydroxide solution. The mixture was finally diluted to $50 \mathrm{~mL}$ adjusted to the optimum $\mathrm{pH}$ for sorption with $0.1 \mathrm{~mol} \mathrm{~L}^{-1} \mathrm{NaOH}$.

\subsubsection{Fish liver}

Fish liver (Makrel fish), obtained from a nearby market in Cairo City, was cut into small pieces and washed several times with distilled water. The sample was transferred into clean and dry glass beaker then dried in oven at $105^{\circ} \mathrm{C}$ for $24.0 \mathrm{~h}$. Next, the dry sample was put into a clean and dry porcelain ignition crucible and heated for $2.0 \mathrm{~h}$ in a muffle furnace at $200^{\circ} \mathrm{C}, 400^{\circ} \mathrm{C}$ and finally at $600^{\circ} \mathrm{C}$, respectively. An accurately weighed 0.4 $\mathrm{g}$ from the final sample was digested in $20 \mathrm{~mL}$ concentrated nitric acid $14.0 \mathrm{~mol} \mathrm{~L}^{-1}$ till nearly dryness. Then, it was made to the optimum $\mathrm{pH}$ by sodium hydroxide solution and diluted to $50 \mathrm{~mL}$ with doubly distilled water. The final solution was passed through the column for preconcentration of the metal ions and the desorbed elements were measured by FAAS ${ }^{[45]}$.

\subsubsection{Tap water}

Tap water sample was collected from our research laboratory at chemistry department (Ain-Shams University). It was filtered to remove any suspended particulates, adjusted to $\mathrm{pH} 6.5$ with $0.01 \mathrm{~mol} \mathrm{~L}^{-1}$ nitric acid and immediately analyzed by passing the sample through the column at flow rate $1 \mathrm{mLmin}^{-1}$. The column was rinsed with distilled water and the sorbed metal ions were eluted by $10 \mathrm{~mL}$ from $0.5 \mathrm{~mol} \mathrm{~L}^{-1} \mathrm{HCl}$ and the desorbed element was measured by FAAS.

\subsubsection{Pharmaceutical sample}

Kerovit is a pharmaceutical preparation which is widely receipted for activity, vitality and memory improvment. This is producted by Amoun pharmaceutical Co. SAE (El-Obour City, Cairo, Egypt). Each capsule contains trace elements $(7.5 \mathrm{mg}) \mathrm{Zn},(2.0 \mathrm{mg})$ each of $\mathrm{Cu}$ and $\mathrm{Mn}$ in addition to multivitamins and supplements. Analysis was carried out by taking one capsule in about $20 \mathrm{~mL}$ concentration $\left(14.0 \mathrm{~mol} \mathrm{~L}^{-1}\right) \mathrm{HNO}_{3}$ and heating for about 30 min until dissolving all constitutes in the capsule the mixture was adjusted to optimized $\mathrm{pH}$ and diluted to $1000 \mathrm{~mL}$. An aliquot $50 \mathrm{~mL}$ from the final solution was analyzed according to the proposed methodology ${ }^{[46]}$.

\section{Results and discussion}

\subsection{Characterization of AA-PUF}

The IR spectral data of the untreated PUF and AA-PUF materials were compared. Two new bands have been observed in AA-PUF at 1657 and $1603 \mathrm{~cm}^{-1}$ which can be due to carbonyl $(\mathrm{C}=\mathrm{O})$ in acetyl acetone and $-\mathrm{N}=\mathrm{N}-$ groups, respectively. As show in Fig. 1. 


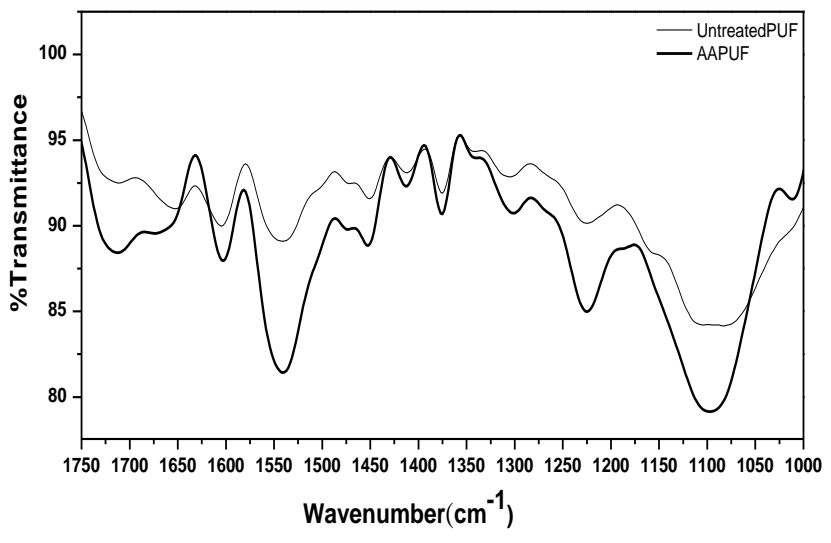

Fig. 1: IR spectra of the PUF phase and modified AA-PUF.

The elemental analysis data for untreated PUF were (found: C, 56.3; H, 7.71; N, 5.25; calculated for $\mathrm{C}_{78} \mathrm{H}_{126} \mathrm{~N}_{6} \mathrm{O}_{30}: \mathrm{C}, 57.6 ; \mathrm{H}, 7.74 ; \mathrm{N}, 5.16 \%$ ); and for AA-PUF were (found: $\mathrm{C}, 59.3 ; \mathrm{H}, 5.6 ; \mathrm{N}, 5.75$; calculated for $\mathrm{C}_{83} \mathrm{H}_{131} \mathrm{~N}_{7} \mathrm{O}_{32}: \mathrm{C}, \underline{57.34} ; \mathrm{H}, \underline{7.54} ; \mathrm{N}$, $5.6 \%$ ). The data indicated one $\mathrm{AA}$ molecule was coupled to the average empirical formula of untreated PUF finally; the overall data confirmed the anchoring of AA to PUF in the first step as presented in Fig. 2.

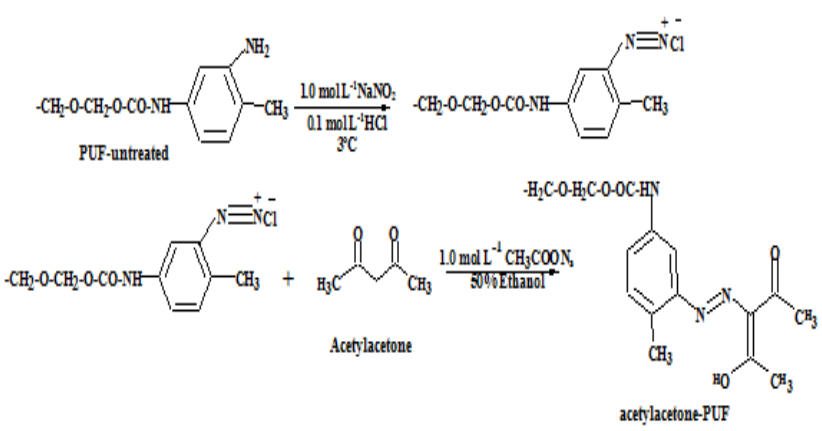

Fig. 2: Structural formulae of AA-PUF Sorbents.

Thermo gravimetric analysis curves are presented in Fig. 3. The anchored surface presented an additional mass loss due to the acetylacetone moieties bonded to the foam backbone, mass loss of $6 \%$ within the temperature range $250-320^{\circ} \mathrm{C}$ which is corresponding to molecular mass of $104 \mathrm{~g} \mathrm{~mol}^{-1}$. From the proposed molecular formula of AA-PUF, the molecular mass of AA moiety is $98 \mathrm{~g} \mathrm{~mol}^{-1} 1$ which compromise $5.6 \%$ mass in AA-PUF material. Therefore, the mass loss may be due to the loss of the coupled AA unit attached to terminal amino group in PUF. As can be seen from the structure in Fig. 1. The second mass loss of 5.9\% beginning at $352^{\circ} \mathrm{C}$ up to $420^{\circ} \mathrm{C}$ that corresponding due to decomposition of PUF similar to untreated PUF reaching final degradation of methylene residue AAmethyl.

${ }^{1} \mathrm{H}-\mathrm{NMR}$ spectroscopic analysis for structure elucidation of the sorbents was done by dissolution of the polymer in dimethylsulfoxide after addition of few drops from triflouroacetic acid to increase the solubility of the polymer. Fig. 4 showed the ${ }^{1}$ H-NMR spectra of AA-PUF.

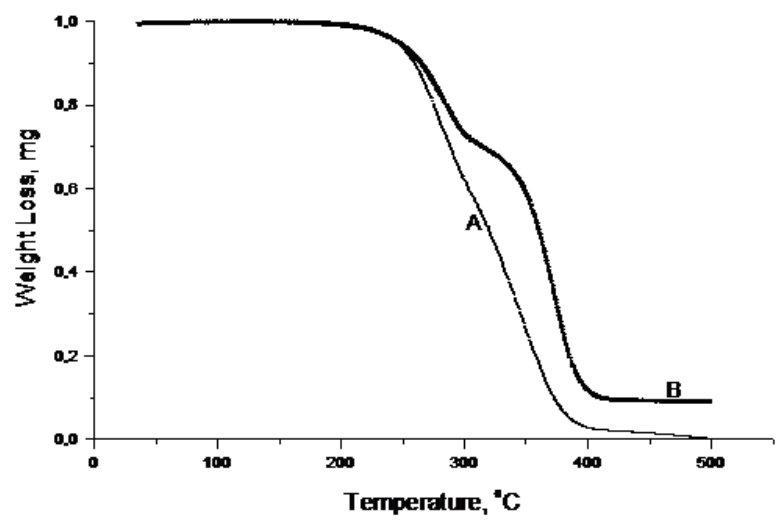

Fig. 3: TGA curves for untreated PUF (A) and AA-PUF (B).

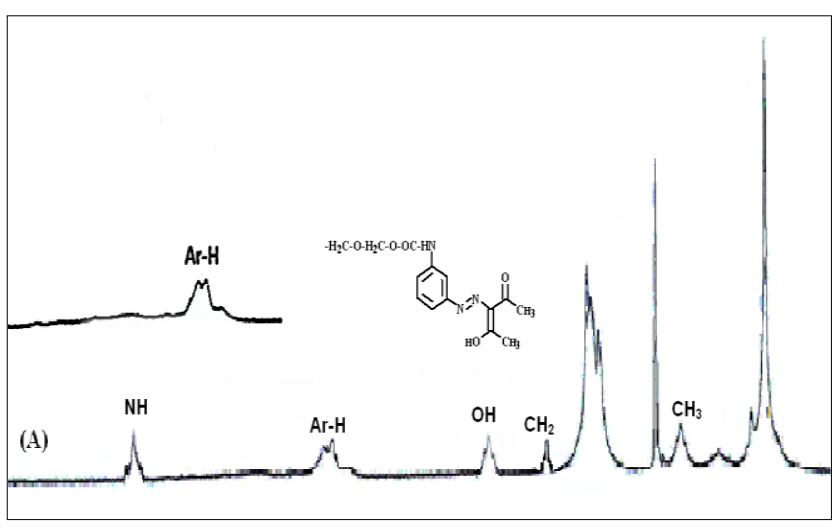

Fig. 4: ${ }^{1} \mathrm{H}$ NMR spectra for AA-PUF (A).

The important peaks in PUF are characterized to $\mathrm{CH}_{3}-1.5$ ppm, $\mathrm{CH}_{2}-1.9-2.0$ ppm, $\mathrm{CH}-3.5-3.7$ ppm, aliphatic $\mathrm{OH}-3.9 \mathrm{ppm}$, The $\mathrm{CH}_{2}$ proton is appeared at $2.3 \mathrm{ppm}$. A sharp peak at $2.7 \mathrm{ppm}$ is depicted to the $=\mathrm{CH}_{2}$. In spectrum (A), a singlet beak observed at 8.5 pp attributed to the $\mathrm{NH}$ in urethane group but no peaks have appeared around $7.5 \mathrm{ppm}$. Two in spectrum (B) characteristic peaks were observed at 8.5 and $9.42 \mathrm{ppm}$ standing for the chemical -NH in PUF.

UV-Vis spectra of the PUF and AA-PUF were measured to confirm the chemical modification. A thin film from the foam material was placed in DMF as blank in quartz cell and the absorbance was recorded Fig. 5. The untreated PUF showed no absorption peaks in the estimated wavelength range from 550 to $300 \mathrm{~nm}$. While that for AA-PUF $570-585 \mathrm{~nm}$. This confirmed the color change from white (untreated PUF) to yellow (AA-PUF).

\subsection{Batch method}

\subsubsection{Influence of solution $\mathrm{pH}$}

The influence of $\mathrm{pH}$ on extraction was investigated in the range 3-8. The results are presented in Fig. 6. Maximum recovery was achieved for copper, Zinc and Manganese at $\mathrm{pH}$ 6, has indicated great improvement in recovery of metal ions, an enhancement in recovery by AA-PUF contains only the two carbonyl oxygen atoms. 
The sorbent contain the two azo nitrogen atoms which couple AA to the PUF backbone. Therefore, the improvement in sorption characteristics for metals in AA-PUF might be due to the extra two nitrogen atoms. These elements are well known to have good affinity to nitrogen containing compounds ${ }^{[35,47]}$. Manganese ions form more stable complexes with oxygen atoms than nitrogen, all elements showed a decrease in recovery at $\mathrm{pH} \geq 7$ which could be due to precipitation of metal hydroxides.

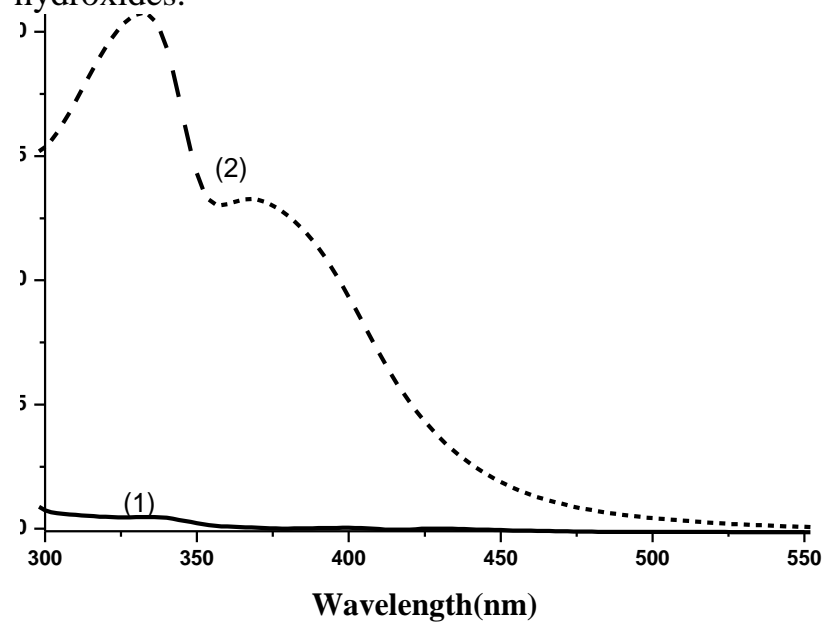

Fig. 5: UV-Vis absorption spectra of untreated-PUF (1) and AAPUF (2)

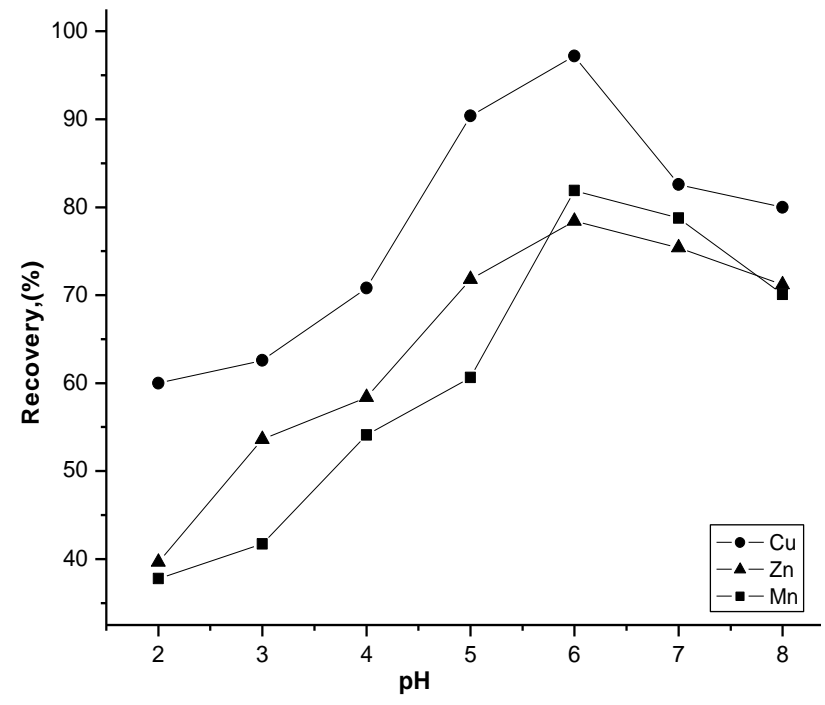

Fig. 6: Influence of sample $\mathrm{pH}$ on the recovery of $\mathrm{Cu}(\mathrm{II}), \mathrm{Zn}(\mathrm{II})$ and $\mathrm{Mn}$ (II) $\left(0.5 \mu \mathrm{g} \mathrm{ml}^{-1}, 10 \mathrm{ml}\right.$ sample with $\left.1 \mathrm{~g}\right)$ AA-PUF.

\subsection{Sorption Kinetics}

The effect of shaking time on the sorption of metal ions by the foam sorbents was investigated in the selected shaking intervals 5, 10, 15, 2025 and $30 \mathrm{~min}$. This parameter is important to envisage the minimum time necessary to achieve maximum extraction. Results showed that copper, Zinc and Manganese reached maximum sorption after $25 \mathrm{~min}$ with the sorbent. The identified recovery percentage for $\mathrm{Cu}(\mathrm{II}), \mathrm{Zn}(\mathrm{II})$ and $\mathrm{Mn}$ (II) were 85,74 and $80 \%$, respectively, after $20 \mathrm{~min}$ shaking time. This slightly fast extraction in case of $\mathrm{Cu}$ (II) and $\mathrm{Mn}$ (II) is indicative of diffusion of metal ions throughout a hypothetical film or hydrodynamic boundary ${ }^{[48]}$.

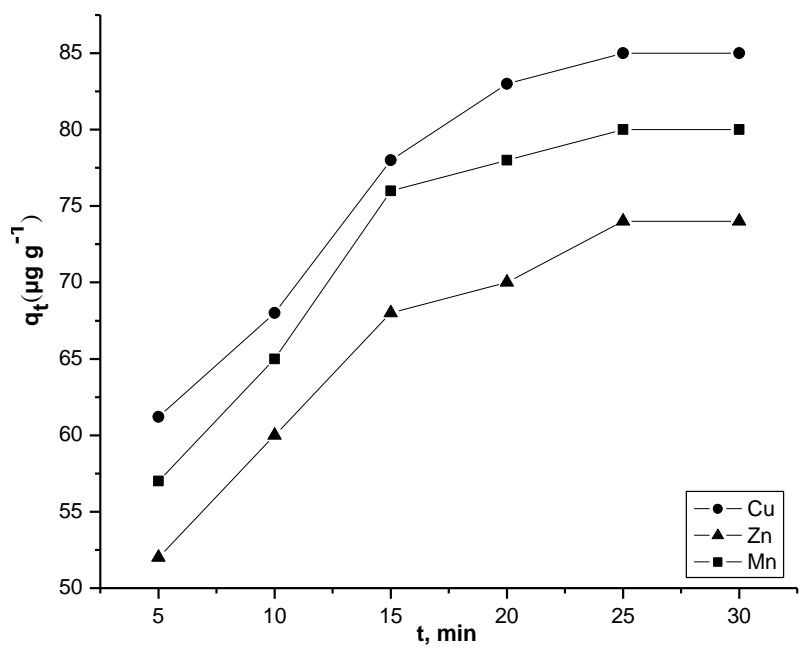

Fig. 7: Effect of shaking time on sorption of $\mathrm{Cu}(\mathrm{II}), \mathrm{Zn}(\mathrm{II})$ and $\mathrm{Mn}$ (II) sorbed $\left(\mu \mathrm{g} \mathrm{g}^{-1}\right)$ by AA-PUF as function of (t, min) at concentration $0.5 \mu \mathrm{g} \mathrm{mL}^{-1}, \mathrm{pH} 6,10 \mathrm{~mL}$ volume of sample, weight of sorbent $0.1 \mathrm{~g}$ and temperature $25^{\circ} \mathrm{C}$

\subsection{Kinetic models}

The kinetic mechanism controlling the adsorption of the metal ion was obtained by applying the pseudo first-order to fit the experimental results. Validity of this model could be investigated by analyzing the linear graphs obtained from plotting of $\log \left(\mathrm{q}_{\mathrm{e}}-\mathrm{q}_{\mathrm{t}}\right)$ versus $\mathrm{t}$, where $q_{e}$ and $q_{t}$ are the sorbed metal ion $\left(\mu g g^{-1}\right)$ at equilibrium and at any time $\mathrm{t}(\mathrm{min})$, respectively. The pseudo-first-order rate equation given by Lagergren and Kungliga ${ }^{[49]}$ can be represented by:

$$
\log \left(q_{\mathrm{e}}-\mathrm{q}\right)=\log \mathrm{q}_{\mathrm{e}}-\mathrm{k}_{1} \mathrm{t} / \mathbf{2 . 3 0 3}
$$

The obtained results are shown Fig. 8. The linear correlation coefficient (r) was in range 0.970 to 0.990 . This indicates that this pseudo-first order model is inconvenient for an interpretation of the adsorption kinetics data.

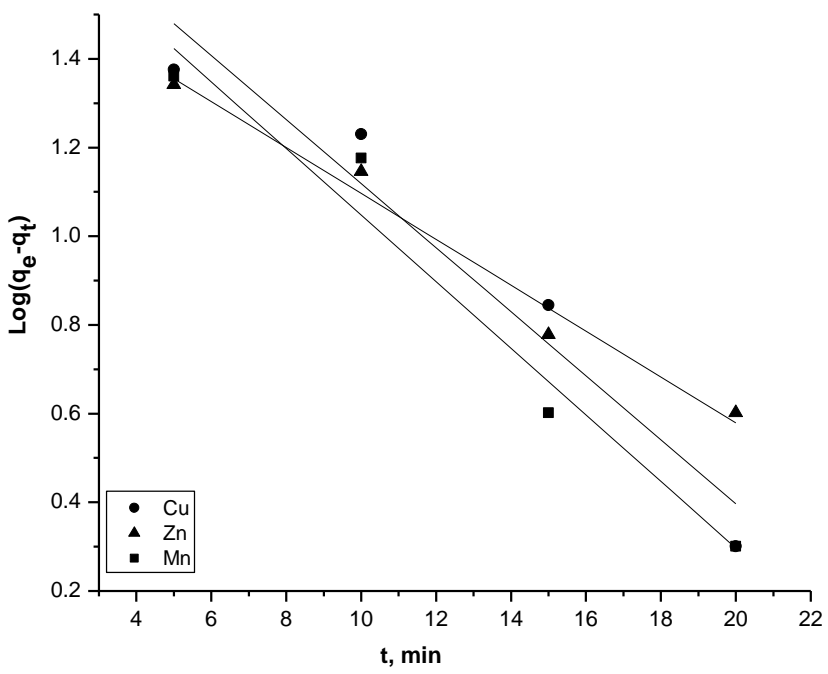

Fig. 8: Lagragren plotting for metal ions at concentration $0.5 \mu \mathrm{g}$ $\mathrm{mL}^{-1}, \mathrm{pH} 6$ (AA), $10 \mathrm{~mL}$ volume of sample, weight of sorbent $0.1 \mathrm{~g}$ and temperature $25^{\circ} \mathrm{C}$ 
According to the pseudo-second order equation ${ }^{[50]}$, in the particals model the $\mathrm{k}_{2}$ is the pseudo-second-order

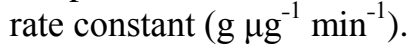

$$
\mathbf{t} / \mathbf{q}_{\mathrm{t}}=\mathbf{1} /\left(\mathbf{k}_{\mathbf{2}} \mathbf{q}_{\mathrm{e}}{ }^{2}\right)+\left(\mathbf{1} / \mathbf{q}_{\mathrm{e}}\right) \mathbf{t}
$$

The model for $\mathrm{Cu}(\mathrm{II})$ sorption provided a better correlation coefficients $\mathrm{R}=0.9994$. From the slope of the regression equation, the $\mathrm{q}_{\mathrm{e}}$ obtained values were $94.60 \mu \mathrm{g} \mathrm{g}^{-1}$, which are in good agreement with the $\mathrm{q}_{\mathrm{e}}$ values obtained experimentally; similar data were obtained which fit very well to the pseudo-second order kinetic model as indicated in Fig. 9. The kinetic results obtained for $\mathrm{Cu}(\mathrm{II}), \mathrm{Zn}$ (II) and $\mathrm{Mn}(\mathrm{II})$ by employing the pseudo second-order kinetics model are complied in Table 1. Better correlation coefficient were obtained, they were in the range 0.998 to 0.999

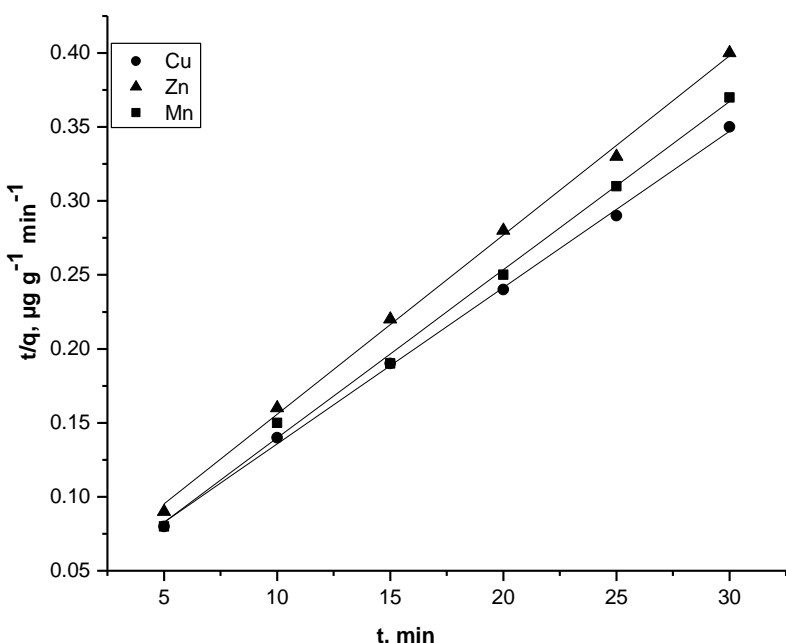

Fig. 9: Pseudo-second order plotting for first order kinetics model for $\mathrm{t} / \mathrm{q}_{\mathrm{t}}$ versus time $\mathrm{t}$ at concentration $0.5 \mu \mathrm{g} \mathrm{mL} \mathrm{L}^{-1}, \mathrm{pH} 6$ (AA), 10 ${ }^{\circ} \mathrm{mL}$ volume of sample, weight of sorbent $0.1 \mathrm{~g}$ and temperature 25

Table 1. Adsorption kinetic data obtained from pseudo-first and pseudo-second order model at $25^{\circ} \mathrm{C}$

\begin{tabular}{|c|c|c|c|c|c|c|c|}
\hline \multirow[b]{2}{*}{ Metal ion } & \multirow[b]{2}{*}{$\begin{array}{l}q_{\exp } \\
\left(\mu g^{-1}\right)\end{array}$} & \multicolumn{3}{|c|}{ Pesudo first-order } & \multicolumn{3}{|c|}{ Pesudo Second-order } \\
\hline & & $\begin{array}{l}\mathrm{q}_{\mathrm{e}} \\
\left(\mu \mathrm{g} \mathrm{g}^{-1}\right)\end{array}$ & $\begin{array}{l}\mathbf{K}_{1} \\
\left(\min ^{-1}\right)\end{array}$ & $\mathbf{R}^{2}$ & $\begin{array}{l}q_{\mathrm{e}} \\
\left(\mu \mathrm{g} \mathrm{g}^{-1}\right)\end{array}$ & $\begin{array}{l}\mathrm{K}_{2} \\
\left(\mathrm{~g} \mu \mathrm{g}^{-1} \min ^{-1}\right)\end{array}$ & $\mathbf{R}^{2}$ \\
\hline $\mathrm{Cu}$ (II) & 85 & 69.26 & 0.166 & 0.970 & 94.60 & $3.72 \times 10^{-3}$ & 0.999 \\
\hline Zn (II) & 74 & 41.11 & 0.119 & 0.990 & 82.57 & $4.23 \times 10^{-3}$ & 0.999 \\
\hline Mn (II) & 80 & 62.87 & 0.173 & 0.982 & 87.95 & $4.97 \times 10^{-3}$ & 0.998 \\
\hline
\end{tabular}

Observed from above table, the $\mathrm{Zn}$ with AA-PUF has lower value of rate constant than with $\mathrm{Cu}$ and $\mathrm{Mn}$, that's congruent with Fig. 7. On other hand the rate constant of $\mathrm{Cu}$ at AA-PUF is higher as shown in Fig. 7, but The $\mathrm{Zn}$ with AA-PUF lower curve goes quickly to equilibrium. Finally, better satisfaction of the data was achieved when the pseudo second-order kinetics model was applied and more likely to fit the adsorption process.

The mechanism of the intra particle diffusion model was investigated applying the Morris-Weber equation ${ }^{[50]}$. Intra-particle diffusion rate constant $\mathrm{K}_{\mathrm{d}}\left(\mu \mathrm{g} \mathrm{g}^{-1}\right.$ $\min ^{-1 / 2}$ ) was verified from the slope for the plot of $q_{t}$ values versus the square root of shaking time $t$.

$$
\mathbf{q}_{\mathbf{t}}=\mathbf{K}_{\mathrm{d}} \mathbf{t}^{1 / 2}
$$

The obtained correlation coefficients(r) were 0.973 to 0.989 which are lower than pseudo-second order. The values of $\mathrm{K}_{\mathrm{d}}$ for the studied elements $\mathrm{Cu}$ (II), $\mathrm{Zn}$ (II) and $\mathrm{Mn}(\mathrm{II})$ are 40.494, 34.848 and $38.246 \mu \mathrm{g} \mathrm{g}{ }^{-1} \mathrm{~min}^{-1 / 2}$ respectively. For AA-PUF, the highest $\mathrm{K}_{\mathrm{d}}$ value was observed for $\mathrm{Cu}$ followed by $\mathrm{Mn}$ and finally $\mathrm{Zn}$.

\subsection{Sorption Isotherm}

The sharp increase in sorption of metal ions are observed in below Fig. 11, with increase in concentration from 1 to $10 \mu \mathrm{gL}^{-1}$, and when $\mathrm{M}$ (II) ions concentration increases from 15 to $25 \mu \mathrm{gL}^{-1}$, results in low sorption capacity its approximately constant sharp. These results demonstrate that the formation of adsorp-

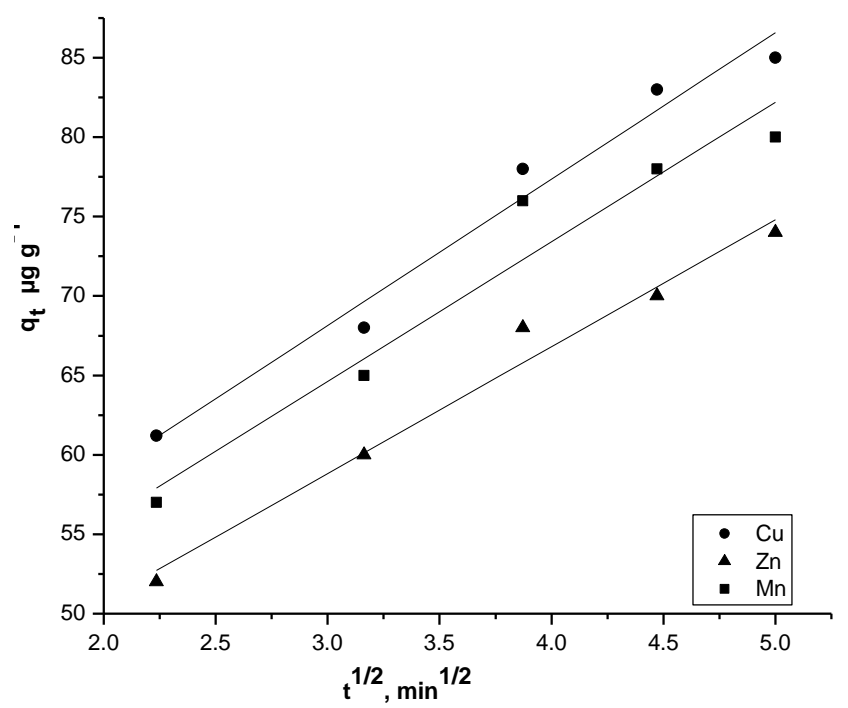

Fig. 10: Plotting of intra-particle diffusion model for metal ions = $0.5 \mu \mathrm{g} \mathrm{mL} \mathrm{m}^{-1}, \mathrm{pH} 6$ (AA), $10 \mathrm{~mL}$ volume of sample, weight of sorbent $0.1 \mathrm{~g}$ and temperature $25^{\circ} \mathrm{C}$.

tion exists as physical adsorption and chemical adsorption. The adsorption is sensitive to the change under the low concentration of electrolyte, which shows that the sorption is dominated by the electrostatic attraction (physical adsorption) ${ }^{[51]}$. 


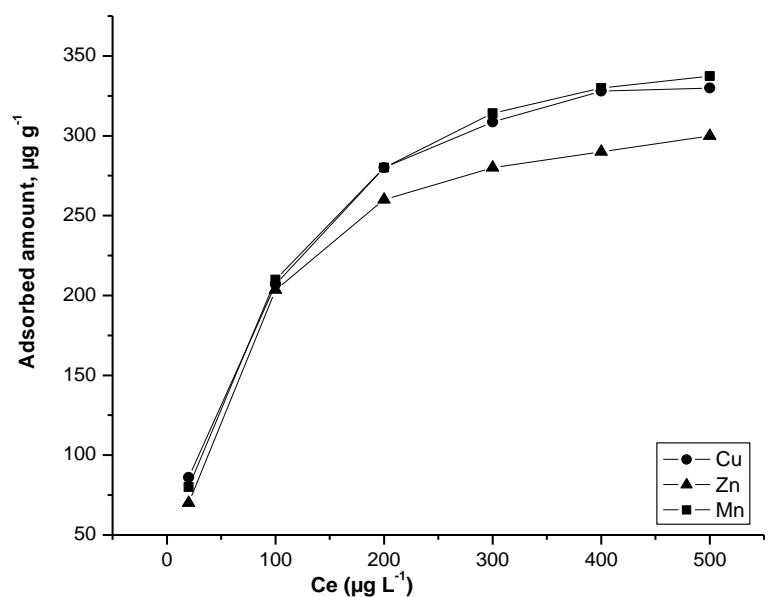

Fig. 11: Extraction isotherm of Copper, Zinc and Manganese with AA-PUF sorbent $\left(0.5 \mu \mathrm{gml}^{-1}, \mathrm{pH} 6,10 \mathrm{~mL}\right.$ volume of sample, weight of sorbent $0.1 \mathrm{~g})$.

\subsubsection{Langmuir model}

The Langmuir isotherm was used to model sorption equilibrium data ${ }^{[52]}$. From the analysis of isotherm, the value of the sorption capacity, the concentration of $\mathrm{Cu}(\mathrm{II}), \mathrm{Zn}$ (II) and $\mathrm{Mn}$ (II) ions, and the mathematical equation of isotherm were placed in a linear form more suitable for determination of sorption parameters. Langmuir isotherms which are described by the equation given below:

$$
\mathrm{C}_{\mathrm{e}} / \mathrm{q}_{\mathrm{e}}=\mathbf{1} / \mathrm{q}_{\max } \mathrm{K}_{\mathrm{L}}+\mathrm{C}_{\mathrm{e}} / \mathbf{q}_{\max }
$$

Where $\mathrm{q}_{\max }\left(\mu \mathrm{gg}^{-1}\right)$ is the maximum amount of metal ion per weight to form a complete monolayer equilibrium metal ion concentration $\mathrm{C}_{\mathrm{e}}\left(\mu \mathrm{gL}^{-1}\right)$ and $\mathrm{K}_{\mathrm{L}}$ is the Langmuir constant related to the affinity of binding sites. The plot of Langmuir model for AA-PUF is presented in Fig. 12.

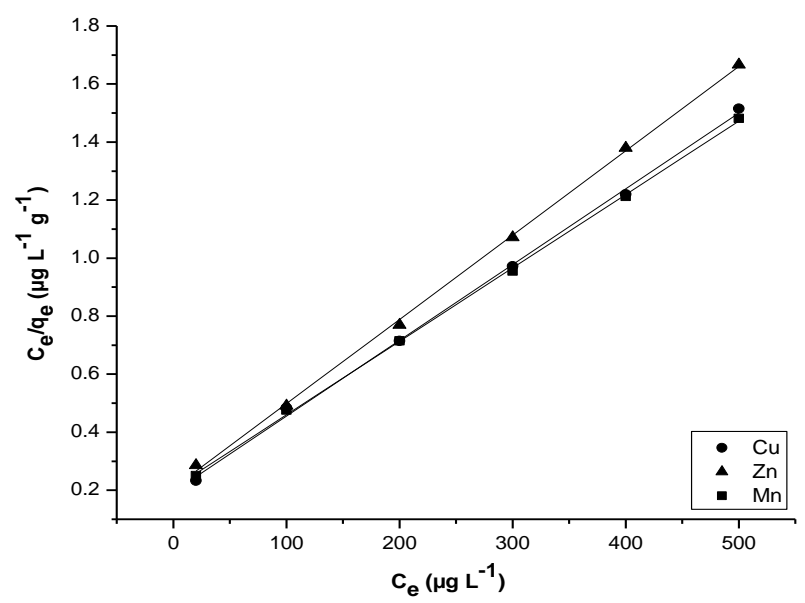

Fig. 12: Langmuir model of Copper, Zinc and manganese with AA-PUF
Fig. 12. The results afforded the regression equation

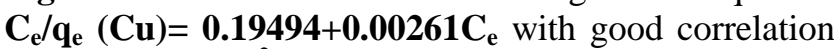
coefficient $\left(\mathbf{R}^{2}=\mathbf{0 . 9 9 9 2 8}\right), \quad \mathrm{C}_{\mathrm{e}} / \mathbf{q}_{\mathrm{e}} \quad(\mathbf{Z n})=$ 0.20778+0.00291C $\mathrm{C}_{\mathrm{e}}\left(\mathbf{R}^{2}=\mathbf{0 . 9 9 9 6 3}\right)$ and $\mathrm{C}_{\mathrm{e}} / \mathrm{q}_{\mathrm{e}}(\mathrm{Mn})=$ 0.20702+0.00253Ce, $\left(\mathbf{R}^{2}=\mathbf{0 . 9 9 9 7 2}\right)$. From previous equation, it was possible to calculate the parameters $\mathrm{q}_{\mathrm{m}}$ that were $\underline{383.14}, \underline{343.64}$ and $\underline{395.25}{\mu \mathrm{g}^{-1}}^{-1}$, respectively. The equation suggests that the Langmuir model is reasonable in interpreting the experimental data. So the values of the $\mathrm{q}_{\mathrm{m}}$ of AA-PUF for $\mathrm{Cu}, \mathrm{Zn}$ and $\mathrm{Mn}$ adsorption is similar with the experimental value $(\underline{330}$, $\underline{300}$, and $\left.\underline{337} \mu \mathrm{g}^{-1}\right)$.

\subsubsection{Freundlich model}

The Freundlich model is an empirical equation used to estimate the adsorption intensity of the sorbent towards the adsorbate. The Freundlich isotherm can be represented by the following equation

$$
q_{e}=K_{F} C e^{1 / n}
$$

Where, $\mathrm{K}_{\mathrm{F}}$ and $\mathrm{n}$ are the Freundlich constant which determines the curvature and steepness of the isotherm. Also, the value of (n) indicates the affinity of the sorbate. The above equation is linearlized as:

$$
\log q_{e}=\log K_{F}+(1 / n) \log C_{e}
$$

A plot of $\log \mathrm{C}_{\mathrm{e}}$ against $\log \mathrm{q}_{\mathrm{e}}$ yielding a straight line indicates the conformation of the Freundlich isotherm. The constants $1 / \mathrm{n}$ and $\log \mathrm{K}_{\mathrm{F}}$ can be determined from the slope and intercept, respectively.

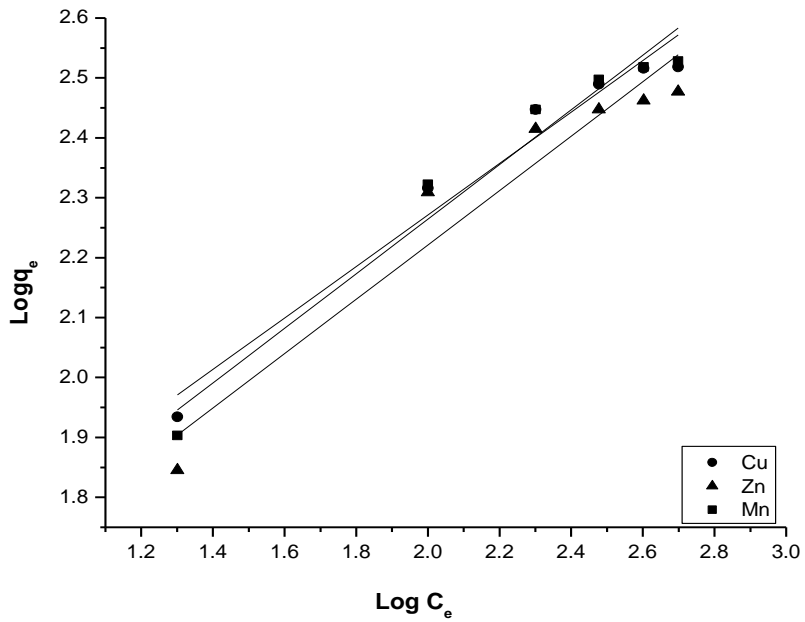

Fig. 13: Freundlich model of Copper, Zinc and manganese with AA-PUF.

Shown in Table 2 . The correlation coefficients $\left(\mathrm{R}^{2}\right)$ and the experimental data have proved that adsorption is well correlated to Langmuir model than Freundlich model. Comparison of the obtained isothermal data is

\begin{tabular}{|c|c|c|c|c|c|c|}
\hline \multirow{2}{*}{ Metal ion } & \multirow{2}{*}{$\begin{array}{l}\mathbf{q}_{\max } \\
\left(\mu g^{-1}\right)\end{array}$} & \multicolumn{2}{|c|}{ Langmuir parameters } & \multicolumn{3}{|c|}{ Freundlich parameters } \\
\hline & & $q_{\max }\left(\mu g g^{-1}\right)$ & $\mathbf{R}$ & $\mathbf{N}$ & $\mathbf{K}\left(\mathbf{L ~ g ~}^{-1}\right)$ & $\mathbf{R}$ \\
\hline $\mathrm{Cu}(\mathrm{II})$ & 330 & 383.14 & 0.9992 & 2.326 & 25.812 & 0.983 \\
\hline $\mathrm{Zn}(\mathrm{II})$ & 300 & 343.64 & 0.9996 & 2.202 & 20.569 & 0.967 \\
\hline $\operatorname{Mn}(\mathrm{II})$ & 337.4 & 395.25 & 0.9997 & 2.193 & 22.519 & 0.981 \\
\hline
\end{tabular}
depicted in Table 2 shown below

Table 2. Isotherm parameters obtained form langmiur and freundlich models 
From the Table 2 showed that the rate of adsorption of metal ions on AA-PUF obeyed a Langmuir kinetic model. Difference in exchange capacities of metal ions may be attributed to their different ionic sizes, degree of hydration and the value of their binding constant with the adsorbent ${ }^{[53,54]}$.

\subsection{Sample flow rate}

Sample flow rate is a measure of the contact time between the metal ion in the sample liquid phase and the solid sorbent. The lower the flow rates the longer the contact time and the larger extent of metal binding. An aliquot of $5 \mathrm{ml}$ at concentration $0.5 \mu \mathrm{g} \mathrm{mL}$ individual metal ion solutions were adjusted at $\mathrm{pH}$ 6-7 and introduced into a packed column containing $1 \mathrm{~g}$ sorbent at varying rates from 0.25 to $2.0 \mathrm{~mL} \mathrm{~min}^{-1}$. For AA-PUF, at flow rates up to $1 \mathrm{~mL} \mathrm{m^{-1 }}$ a constant and maximum recovery was observed for $\mathrm{Cu}$ while recovery of $\mathrm{Zn}$ and $\mathrm{Mn}$ was similar Fig.14. The results showed that flow rate variations in the range of 0.25 $1.0 \mathrm{~mL} \mathrm{~min}^{-1}$ a gradual decrease in recovery was observed while higher flow rates than $1.0 \mathrm{~mL} \mathrm{~min}{ }^{-1}$ had no significant effect on the sorption of the metal ion Fig.14. For achievement of a good precision, a flow rate of $1.0 \mathrm{~mL} \mathrm{~min}{ }^{-1}$ was chosen for subsequent experiments. However, higher flow rates up to $2.0 \mathrm{~mL}$ $\min ^{-1}$ could be employed when the sample concentration is too low to benefit of a decrease in analysis time but on the expense of method precision.

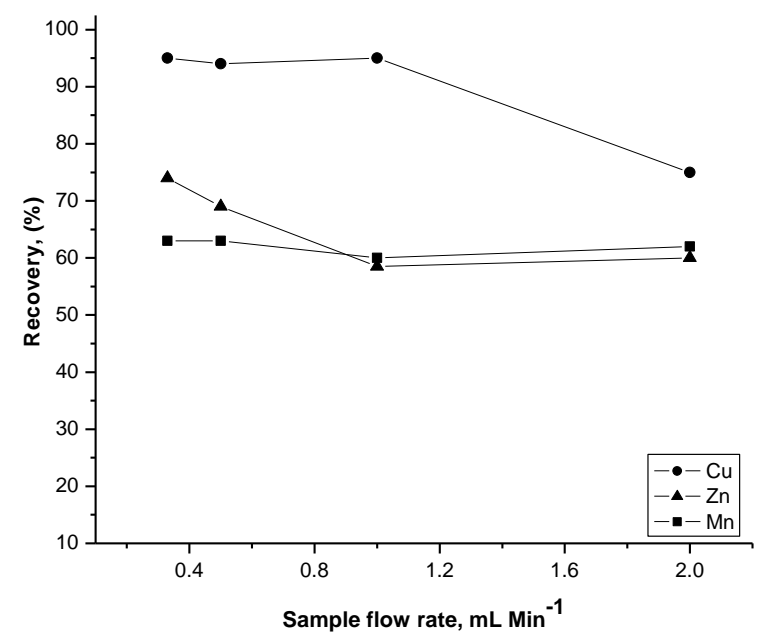

Fig. 14: Effect of sample flow rate on the recovery of $\mathrm{Cu}, \mathrm{Zn}$ and Mn with AA-PUF sorbent at $\mathrm{pH} 6,0.5 \mu \mathrm{g} \mathrm{mL}^{-1}, 10 \mathrm{ml}$ samples and $1.0 \mathrm{~g}$ foam

\subsection{Desorption metal ions}

Eluent type can influence both of the lifetime of the sorbent of the method. The usage of complexing agents like thiourea or EDTA was excluded as it might be sorbed into the foam matrix thus causing chemical changes in the nature of foam surface leading to irreproducible recovery data.

Hydrochloric and nitric acids are presumed to be the most suitable for desorption of the bound metal ions. The most frequently used is hydrochloric acid because it is suitable with its non-oxidative effect in controversy to nitric acid.
Universally, dilute mineral acids was found effective for removal of metal ions from PUF based sorbents ${ }^{[55]}$. However, at too low acid concentration the amount of protons may be not enough to protonate the chelation site to exchange with bounded metal ion. High acid concentration was not used for desorption due to increasing the volume of eluate by the need for its neutralisation prior to FAAS determination that would reduce the preconcentration factor or contamination from acid. Therefore, concentration of hydrochloric acid was carefully optimized. For this purpose, the metal ions were eluted from the column with $10 \mathrm{~mL}$ of $\mathrm{HCl}$ of varying concentration between 0.2 and $0.7 \mathrm{~mol} \mathrm{~L}^{-1}$ at optimum flow rate. The recovery of $\mathrm{Cu}, \mathrm{Mn}$ and $\mathrm{Zn}$, was quantitative (34-80\%) at acid concentration from 0.3-0.5 mol $\mathrm{L}^{-1}$ as shown in Fig. 15. But it was found no significant difference in the recovery percentage of each metal ion at different concentrations of eluent. Low recovery was achieved for $\mathrm{Mn}$ with AA-PUF at concentration $<0.3 \mathrm{~mol} \mathrm{~L}^{-1}$. Also, at acid concentration more than $0.5 \mathrm{~mol} \mathrm{~L}^{-1}$, the recovery was reduced for most elements which could be due to interference by chloride ion. Accordingly, the $0.4 \mathrm{~mol} \mathrm{~L}^{-1}$ concentration was selected as the optimum eluent concentration for achievement of the highest recovery of each metal ion.

Volume of eluent solution necessary to quantitatively remove $\mathrm{Cu}(\mathrm{II}), \mathrm{Mn}$ (II) and $\mathrm{Zn}$ (II) from the modified sorbents was carefully investigated. It is of great importance to use sufficient volume from the eluent enough to desorb metal ions, however, extra volume will adversely affect the value of preconcentration factor. Elution was effected with volumes from 2.5 to 12 $\mathrm{mL}, 0.4 \mathrm{molL}^{-1}$ hydrochloric acid. Under the specified experimental conditions, recoveries higher than $86 \%$ for AA-PUF was obtained for all elements by employing $8-10 \mathrm{~mL}$ from the eluent. Larger volumes than $10 \mathrm{~mL}$ caused decrease in the recovery percentage which might be due to dilution of the eluate. In order to pursue maximum preconcentration and recovery, a $10 \mathrm{~mL}$ from $0.4 \mathrm{~mol} \mathrm{~L}^{-1}$ hydrochloric acid was employed.

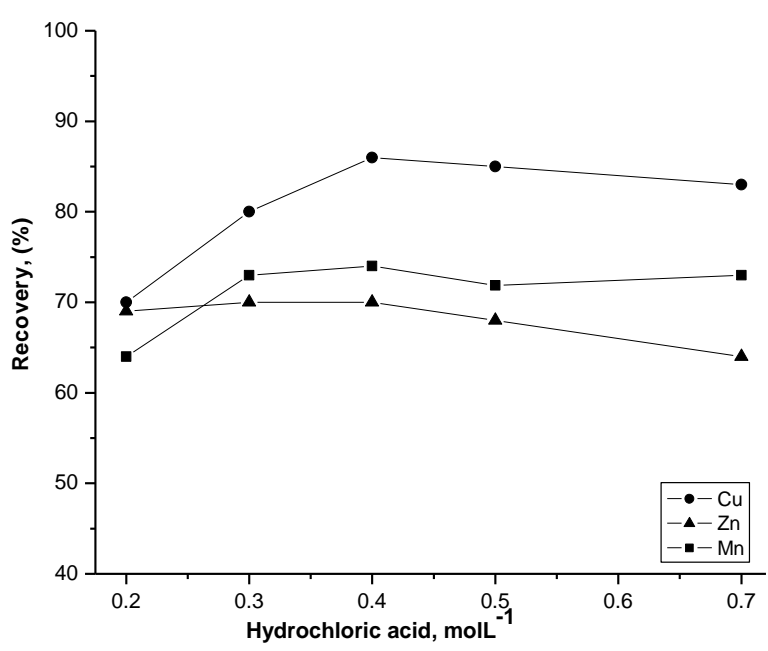

Fig. 15: Effect of hydrochloric acid concentration on the recovery of $\mathrm{Cu}, \mathrm{Zn}$, and $\mathrm{Mn}$ with AA-PUF modified at $\mathrm{pH} 6,10 \mu \mathrm{gL}^{-1}, 10 \mathrm{ml}$ samples and $1 \mathrm{~g}$ foam. 


\subsection{Break through curve}

Values of the working capacities were determined for fixed-bed column packed with $1.0 \mathrm{~g}$ sorbent. The column were percolated with metal ion solution with initial concentration $10 \mu \mathrm{g}$ and adjusted to $\mathrm{pH} 6$ then passed at flow rate $1.0 \mathrm{~mL} \mathrm{~min}^{-1}$. Fixed bed breakthrough curves were obtained to investigate the capability of column operation. Evidently, AA-PUF column could completely remove elements and there was no leakage of metal ion up to $2.5 \mathrm{~mL}$ bed volume. After this volume, the effluent concentration increases gradually with varying different behaviours. The influent-effluent equilibria at point of zero sorption were obtained at 15 for $\mathrm{Cu}$ and 10 for $\mathrm{Zn}$ and $\mathrm{Mn}$. The larger bed volume for $\mathrm{Cu}$ zero-point adsorption could be explained by the less stability for $\mathrm{Cu}$ to the ligand compound where fraction of intervening ions are retained and other fraction went to effluent. Controversy, $\mathrm{Zn}$ reached the saturation point after only $10 \mathrm{~mL}$ from feeding solution was passed which reveals that all $\mathrm{Zn}$ ions are strongly retained to the column without further desorption. Manganese showed intermediate retention characteristics. The working breakthrough capacity could be calculated by the equation:

$$
\mathrm{C}_{\mathrm{w}}=\mathrm{V}_{\mathrm{b}} \cdot \mathrm{C}_{\mathbf{0}} / \mathrm{V}_{\mathrm{s}}
$$

Where $C_{\mathrm{w}}$ is the column working capacity, $V_{\mathrm{b}}$ is the collected volume of effluent between the first fractions and that to the breakthrough point $(\mathrm{mL}), C_{\mathrm{o}}$ is the initial concentration of metal ion, $V_{s}$ is the volume of sorbent bed packed into the column. The working capacities were 15 for $\mathrm{Cu}$ and 10 for $\mathrm{Zn}$ and $\mathrm{Mn}$ in case of AA-PUF, Maximum capacity was observed $150 \mu \mathrm{gg}^{1-}$, $100 \mathrm{\mu gg}^{1-}$ and $100 \mu \mathrm{gg}^{1-}$ respectively, which reveals good retention of the element onto the column which predict good preconcentration capability and low limit of detection. The order of capacity is in the following order.

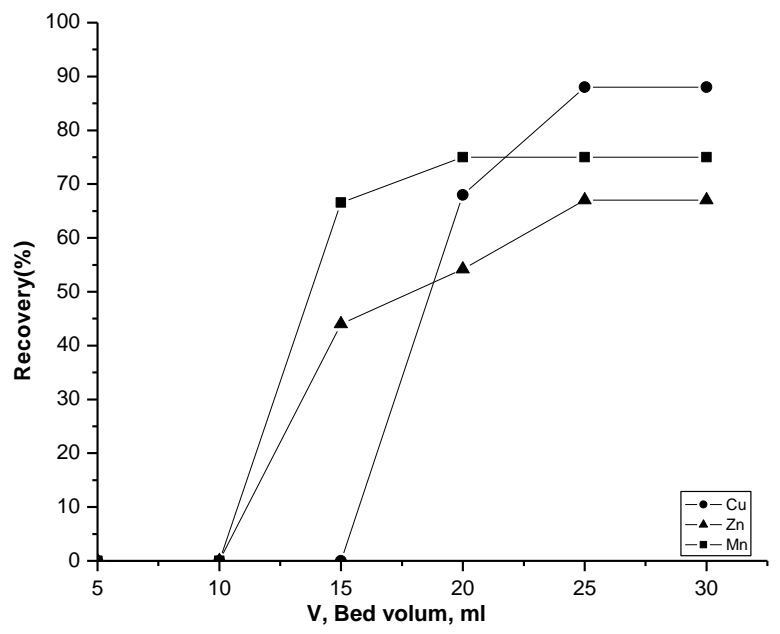

Fig. 16: Breakthrough curves for $\mathrm{Cu}, \mathrm{Zn}$, and $\mathrm{Mn}$ solution $\left(10 \mu \mathrm{gl}^{-1}\right)$ with AA-PUF foam at $1 \mathrm{ml} \mathrm{min}{ }^{-1}, \mathrm{pH} 6$ and $1 \mathrm{~g}$ foam sorbent.

\subsection{Interference effect}

The potential interferences of some foreign ions that might be sorbed onto AA-PUF were investigated in order to identify influence on sorption. The sorption of metal ions in the presence of common ions or complexing agents may be affected due to precipitation, complex formation or competition for sorption sites. Ten milliliter model solution containing $0.5 \mu \mathrm{g} \mathrm{mL}^{-1}$ $\mathrm{Cu}, \mathrm{Zn}$ or $\mathrm{Mn}$ was adjusted to optimum $\mathrm{pH}$ and passed through the column at flow rate $1.0 \mathrm{~mL} \mathrm{~min}^{-1}$. The concentration of the added foreign ions was gradually increased in the sample. The tolerance levels were taken as the maximum concentration of foreign ion that caused a change in recovery by $\pm 5 \%$ compared with reference volume. Cations examined were: $\mathrm{Na}(\mathrm{I}), \mathrm{K}(\mathrm{I})$, $\mathrm{Ca}(\mathrm{II}), \mathrm{Mg}(\mathrm{II}), \mathrm{Fe}(\mathrm{III}), \mathrm{Co}(\mathrm{II}), \mathrm{Ni}(\mathrm{II})$, and $\mathrm{Pb}(\mathrm{II})$, and anions e.g. chloride, sulphate, nitrate, phosphate and oxalate. The obtained results are depicted in Fig. 17. Results showed that AA-PUF extraction of $\mathrm{Cu}$ (II) was affected by the presence of transition elements Fe(III), $\mathrm{Co}(\mathrm{II}), \mathrm{Ni}(\mathrm{II})$, and $\mathrm{Pb}(\mathrm{II})$ and some anions especially chloride and oxalate. While $\mathrm{Zn}$ (II) extraction was strongly affected by $\mathrm{Fe}(\mathrm{III})$ and $\mathrm{Ni}(\mathrm{II})$ in addition to chloride and oxalate. Alkali and alkaline earth elements did not show strong interfering effect on $\mathrm{Cu}$ and $\mathrm{Zn}$ recovery. On the other hand, extraction of $\mathrm{Mn}$ (II) by AA-PUF was adversely affected by $\mathrm{Ca}$ and $\mathrm{Mg}$ ions. The alkaline earth metal ions did not interfere with the extraction. Finally, the effects of most examined foreign ions are found to be negligible which confirms that the studied metals can be determined quantitatively in natural samples with relevant accuracy.

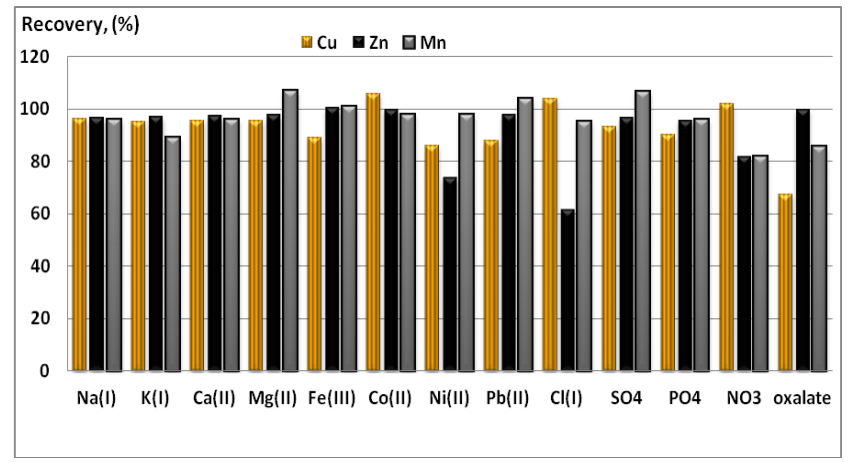

Fig. 17: Influences of some foreign ions on the recoveries of analytes.

\subsection{Influence of sample volume and} preconcentration factor.

Sample volume is directly related to the preconcentration factor (PF). The higher the volume of the sample from which metal ion can be quantitatively preconcentrated, the greater the value of PF. The influences of the volume of sample on the recoveries of $10 \mu \mathrm{gL}^{-1}$ metal ions were studied by varying the sample volume from 100 to $1000 \mathrm{~mL}$ and desorption was affected by a $10 \mathrm{~mL}$ from $0.4 \mathrm{~mol} \mathrm{~L}^{-1} \mathrm{HCl}$ eluent solution. The obtained results are summarized in Table 3. 
Quantitative recoveries (93-97\%) were achieved at sample volume in the range of $100-1000 \mathrm{~mL}$ for the investigated metal ions. Above $1000 \mathrm{~mL}$, the recoveries decreased and were not quantitative. Incomplete retention of metal ions could be probably due to the sample itself acted as eluent or less contact of metal ion with the sorbent surface.
Therefore, a sample volume $\leq 1000 \mathrm{~mL}$ was recommended for the simultaneous preconcentration of all metal ions in order to ensure good recovery. A preconcentration factor 100 was obtained by the ratio of the maximum sample volume for each analytes to the eluent volume.

Table 3. Preconcentration of metal ions on $1.0 \mathrm{~g}$ foam column

\begin{tabular}{llllll}
\hline \multirow{2}{*}{ Element } & $\begin{array}{l}\text { Initial volume } \\
(\mathbf{m l})\end{array}$ & $\begin{array}{l}\text { Concentration } \\
\boldsymbol{\mu g L}^{-\mathbf{1}}\end{array}$ & $\begin{array}{l}\text { Desorption } \\
\text { Volume }(\mathbf{m l})\end{array}$ & Recovery $(\boldsymbol{\%})$ & \multirow{2}{*}{ PF } \\
\hline $\mathrm{Cu}(\mathrm{II})$ & 1000 & 10 & 10 & 93.6 & 100 \\
$\mathrm{Zn}(\mathrm{II})$ & 1000 & 10 & 10 & 93.5 & 100 \\
$\mathrm{Mn}(\mathrm{II})$ & 1000 & 10 & 10 & 97.2 & 100 \\
\hline
\end{tabular}

\subsection{Reusability and Precision}

Reusability test was studied because it indicates the number of preconcentration cycles the column can be used without losing its analytical efficiency. Indeed, the whole experimental work was carried out on the same sorbent plugs either as packed column or in batch methodology. There was no need to replace the plugs since it gave quantitative sorption from time to time. Therefore, the reusability could be obtained by counting the total number of preconcentration cycles in which the plugs were used. It was found that the capacity of the two sorbents was practically constant after its repeated use more than 70 cycles. The use of low concentration hydrochloric acid as an eluent elongate the life time of the sorbent. Finally, the multiple uses of both of sorbent are feasible.

The precision of the determination of copper, zinc and manganese was evaluated under the optimum conditions mentioned for preconcentration by column method. Five samples were prepared identically each contains $10 \mu \mathrm{g}$ metal ion in $10 \mathrm{~mL}$ solution. Individual sample was subjected to several sorption - desorption cycle.
The method precision was estimated as the relative standard deviation (RSD) value for five replicate preconcentration. Results showed good precision (less than $10 \%$ ) where the RSD vary in the range 6.3, 5.3, 3.2 $\%$ of $\mathrm{Cu}, \mathrm{Zn}$ and $\mathrm{Mn}$ respectively.

\subsection{Accuracy}

The standard (Merck) was used to study the accuracy add-found test was used to evaluate the accuracy of the developed preconcentration method. Synthetic samples was prepared from individual metal ion $\left(0.5 \mu \mathrm{gL}^{-1}\right)$ then passed into the preconcentration column under the optimized conditions and the recovery and relative standard deviation RSD\% values were found. The obtained results are complied in Table 4 . The recoveries vary from 84.00 to $91.26 \%$ for AA-PUF. Also, the RSD values are in the range $1.208-4.762 \%$. The results are in good agreement, showing that the proposed method might be used for metal ion determination, even at low concentrations. Finally, the recovery percentage and RSD\% values are extensively efficient for analytical determination of these elements at low concentrations.

Table 4. Accuracy of the method as recovery and RSD values for founded test metal ions

\begin{tabular}{|c|c|c|c|c|}
\hline Element & $\begin{array}{l}\text { Added, } \\
\mu \mathrm{g} \mathrm{mL}^{-1}\end{array}$ & $\begin{array}{l}\text { Found*, } \\
\mu \mathrm{g} \mathrm{mL}^{-1}\end{array}$ & Recovery (\%) & $\begin{array}{l}\text { RSD } \\
(\%)\end{array}$ \\
\hline $\mathrm{Cu}$ & 0.5 & $0.456 \pm 0.005$ & 91.3 & 1.208 \\
\hline $\mathrm{Zn}$ & 0.5 & $0.420 \pm 0.020$ & 84.3 & 4.762 \\
\hline Mn & 0.5 & $0.437 \pm 0.0057$ & 87.3 & 1.321 \\
\hline
\end{tabular}

* Mean value for five measurements.

\subsection{Analytical figures of merit}

The analytical figures of merit of the present procedure using the new sorbents and their determination by FAAS were evaluated under optimal experimental conditions. Linear calibration graphs have been obtained represented by regression equation and correlation coefficient $\left(\mathrm{r}^{2}\right)$ as indicated in Table 5. The values of limit of detection defined as (blank $+3 \mathrm{~s}$ ) where $\mathrm{s}$ is standard deviation of the blank determina- tion are $0.14,0.51$ and $0.148 \mu \mathrm{g} \mathrm{L}{ }^{-1}$ for $\mathrm{Cu}, \mathrm{Zn}$ and $\mathrm{Mn}$ at AA-PUF column, respectively. The corresponding limit of quantification (blank $+10 \mathrm{~s}$ ) values is range 0.16-1.49. The LOD values for AA-PUF which reflect greater sensitivity of the former. Obviously, the limit of detections are less than the concentration of the tested metal ions in the majority of real samples which enables quantification of these elements with sufficient accuracy. 
Table 5. Analytical feature of the modified PUF sorbents

\begin{tabular}{cccccc}
\hline $\begin{array}{c}\text { Metal } \\
\text { ion }\end{array}$ & $\begin{array}{c}\text { Regression } \\
\text { Equation, }\end{array}$ & $\mathbf{r}^{\mathbf{2}}$ & $\begin{array}{c}\text { LOD } \\
\left(\boldsymbol{\mu g L} \mathbf{g L}^{-\mathbf{1}}\right)\end{array}$ & $\begin{array}{c}\text { LOQ } \\
\left(\boldsymbol{\mu g L} \mathbf{g L}^{-1}\right)\end{array}$ & $\begin{array}{c}\text { Linear range } \\
\left(\boldsymbol{\mu g L} \mathbf{L}^{-\mathbf{1}}\right)\end{array}$ \\
\hline $\mathrm{Cu}$ & $\mathrm{A}=0.0683 \mathrm{C}-0.0339$ & 0.994 & 0.144 & 0.37 & $2-20$ \\
$\mathrm{Zn}$ & $\mathrm{A}=0.321 \mathrm{C}+0.1956$ & 0.991 & 0.51 & 1.49 & $2-20$ \\
$\mathrm{Mn}$. & $\mathrm{A}=0.0118 \mathrm{C}+0.006$ & 0.999 & 0.148 & 0.16 & $2-20$ \\
\hline
\end{tabular}

\subsection{Analysis of real samples}

The applicability of the synthesized sorbents was evaluated by analysis of real samples. Firstly, the pharmaceutical preparation Kerovit was analyzed by the proposed method. The obtained results are shown in Table 6. Adequate recovery values were obtained in the range $83.07-91.53 \%$ for AA-PUF. The corresponding RSD values varied in the ranges $1.05-4.13 \%$, which are reasonable. The overall consideration of the recovery data indicates that it is quantitative for all metal ions.

Secondly, the content of metal ions under investigation was determined in biological sample fish liver, and two environmental samples namely olive leaves and drinking water. The obtained results are presented in Table 7. The values for the RSD \% are found to be in the range $1.02-8.3 \%$ which is considered relevant (less than $10 \%$ ) for real samples. The analytical results in Table 7 are in agreement with the some reference methods. It indicates that the proposed method is reliable. The obtained data conferred susceptible accuracy of the developed method based on the satisfactory values of RSD in addition to the reasonably high sensitivity. Finally, satisfactory results were obtained for the elements would confirm good validity of the proposed method for the preconcentration of the investigated metal ions from pharmaceutical and natural.

Table 6. Determination of $\mathrm{Cu}, \mathrm{Zn}$ and $\mathrm{Mn}$ in the pharmaceutical sample Kerovit

\begin{tabular}{ccccc}
\hline $\begin{array}{c}\text { Metal } \\
\text { ion }\end{array}$ & $\begin{array}{c}\text { Reported } \\
(\boldsymbol{\mu g})\end{array}$ & $\begin{array}{c}\text { Found } \\
(\boldsymbol{\mu g})\end{array}$ & $\begin{array}{c}\text { Recovery } \\
(\boldsymbol{\%})\end{array}$ & $\begin{array}{c}\text { RSD } \\
(\boldsymbol{\%})\end{array}$ \\
\hline $\mathrm{Cu}$ & 1.3 & $1.19 \pm 0.049$ & 91.53 & 4.13 \\
$\mathrm{Zn}$ & 5 & $4.55 \pm 0.048$ & 91.00 & 1.05 \\
$\mathrm{Mn}$ & 1.3 & $1.08 \pm 0.015$ & 83.07 & 1.42 \\
\hline
\end{tabular}

Table 7. Determination of metal ions in environmental samples by the developed procedure

\begin{tabular}{|c|l|l|l|}
\hline \multirow{2}{*}{ Sample analyzed } & \multirow{2}{*}{ Metal ion } & \multicolumn{2}{|c|}{ Present Method } \\
\cline { 2 - 4 } & & Found $\left(\boldsymbol{\mu g L}^{-\mathbf{1}}\right)^{*}$ & RSD\% \\
\hline \multirow{3}{*}{ Fish liver } & $\mathrm{Cu}$ & $4.2 \pm 0.087$ & 2.07 \\
\cline { 2 - 4 } & $\mathrm{Zn}$ & $4.24 \pm 2.306$ & 5.43 \\
\cline { 2 - 4 } & $\mathrm{Mn}$ & $4.95 \pm 0.0503$ & 1.02 \\
\hline \multirow{3}{*}{ Olive leaves } & $\mathrm{Cu}$ & $1.05 \pm 0.046$ & 4.38 \\
\cline { 2 - 4 } & $\mathrm{Zn}$ & $3.88 \pm 0.2$ & 5.15 \\
\cline { 2 - 4 } & $\mathrm{Mn}$ & $0.24 \pm 0.02$ & 8.33 \\
\hline \multirow{5}{*}{ Drinking water } & $\mathrm{Cu}$ & $2.4 \pm 0.163$ & 6.80 \\
\cline { 2 - 4 } & $\mathrm{Zn}$ & $0.39 \pm 0.009$ & 2.43 \\
\cline { 2 - 4 } & $\mathrm{Mn}$ & $0.36 \pm 0.016$ & 4.54 \\
\hline
\end{tabular}

*Mean value to four replicate measurements $(n=4)$,

Fish liver and olive leaves $\left(\mu \mathrm{gg}^{-1}\right)$, drinking water $\left(\mu \mathrm{gL}^{-1}\right)$

\section{Conclusions}

In the present work, a simple, rapid, cost effective and reliable method for the determination of trace amounts of $\mathrm{Cu}(\mathrm{II}), \mathrm{Zn}$ (III) and $\mathrm{Mn}$ (II) was developed. Directly attached acetylacetone to polyurethane was synthesized and applied to solid-phase sorbent for determination of metal ions in natural samples by extraction methodology in batch and column modes. Simple and fast preparation of the sorbents under mild reaction conditions to avoid decomposition of polyurethane foam. Recycling the sorbent more than 70 times and preconcentration factor 100 was achieved. The developed methods have been successfully applied to determination of trace metal ions in pharmaceutical, biological and environmental samples. Satisfactory accuracy and precision of the methods were obtained. 


\section{References}

1) S. G. Ozcan, N. Satiroglu, M. Soylak, (2010). Column solid phase extraction of iron(III), copper(II), manganese(II) and lead(II) ions food and water samples on multiwalled carbon nanotubes, Food and Chemical Toxicology, 6: 278-6915.

2) L. Ning, Yang Liyuan, Dai Jirui, Pang Xugui, (2011). Heavy Metal Pollution in Surface Water of Linglong Gold Mining Area, China, Procedia Environmental Sciences 10: 914-917.

3) M. J. M. Sánchez, Mari Luz García-Lorenzo, Carmen Pérez-Sirvent, Jaume Bech, (2012). Trace element accumulation in plants from an aridic area affected by mining activities, Journal of Geochemical Exploration 5: GEXPLO-04972.

4) G. Bonanno, (2012). Arundo donax as a potential biomonitor of trace element contamination in water and sediment, Ecotoxicology and Environmental Safety 80: 20-27

5) C. Ye, Siyue Li, Yulong Zhang, Quanfa Zhang, (2011). Assessing soil heavy metal pollution in the water-level-fluctuation zone of the Three Gorges Reservoir, China, Journal of Hazardous Materials 191: 366-372

6) M. Varol, (2011). Assessment of heavy metal contamination in sediments of the Tigris River (Turkey) using pollution indices and multivariate statistical techniques, Journal of Hazardous Materials 195: 355-364

7) G. Guo, Fengchang Wu, Fazhi Xie, Ruiqing Zhang, (2012). Spatial distribution and pollution assessment of heavy metals in urban soils from southwest China, Journal of Environmental Sciences, 24(3): 410-418.

8) C. Zhang, Qingqing Qiao, D. A. Piper, Baochun Huang, (2011). Assessment of heavy metal pollution from a Fe-smelting plant in urban river sediments using environmental magnetic and geochemical methods, Environmental pollution 157: 3057-3070

9) M. Soylak, O. Ercana, (2009). Selective separation and preconcentration of copper (II) in environmental samples by the solid phase extraction on multi-walled carbon nanotubes. Journal of Hazardous Materials, 168: 1527-1531.

10) V. Camel, (2003). Solid phase extraction of trace elements, Spectrochimica Acta, Part B 58: 1177-1233.

11) A. O. Alnajjar, M. E. El-Zariam, (2008). Synthesis and characterization of novel azo-morphine derivatives for possible use in abused drugs analysis. European Journal of Medicinal Chemistry, 43: 357-363.

12) A. H. Alhashemi, M.S. Sekhavatjou, B. Hassanzadeh Kiabi, A.R. Karbassi, (2012). Bioaccumulation of trace elements in water, sediment, and six fish species from a freshwater wetland, Iran, Microchemical Journal 6: microc-01510.
13) A. Romero, I. González, E. Galán, (2012) Trace elements absorption by citrus in a heavily polluted mining site, Journal of Geochemical Exploration 113: 76-85.

14) S. Demirci Çekiç, Hayati Filik, Ressat Apak, (2004). Use of an o-aminobenzoic acid-functionalized XAD-4 copolymer resin for the separation and preconcentration of heavy metal(II) ions, Analytica Chimica Acta 505: 15-24.

15) F. Huanga, Y. Wua, D. Gua, F. G. Shanghai, (2005). Optical parameters and absorption of copper (II)-azo complexes thin films as optical recording mediaChina, Thin Solid Films, 483: 251-256.

16) G. Sagratini, M. Fernández-Franzón, F. De Berardinis, G. Font, S. Vittori, J. Mañes, (2012). Simultaneous determination of eight underivatised biogenic amines in fish by solid phase extraction and liquid chromatography-tandem mass spectrometry, Food Chemistry 132: 537-543

17) M. Sun, Qianghua Wu, (2012). Cloud point extraction combined with graphite furnace atomic absorption spectrometry for speciation of $\mathrm{Cr}$ (III) in human serum samples, Journal of Pharmaceutical and Biomedical Analysis 60: 14-18

18) K. Nejati, Z. Rezvani, Ma. Seyedahmadian, (2009). The synthesis, characterization, thermal and optical properties of copper, nickel, and vanadyl complexes derived from azo dyes, Dyes and Pigments, 83: 304-311

19) $P$. Morais, Teodor Stoichev, M. Clara P. Basto, M. Teresa S.D. Vasconcelos, (2012). Extraction and preconcentration techniques for chromatographic determination of chlorophenols in environmental and food samples, Talanta 89: 1-11

20) A. Pen alver, E. Pocurull, F. Borrull, R.M. Marce', (2002). Solid-phase microextraction coupled to high-performance liquid chromatography to determine phenolic compounds in water samples, Journal of Chromatography A, 953: 79-87

21) Z. WenJue1, WANG DongHong1, XU XiaoWei1, WANG BingYi1, LUO Qian1, SENTHIL KUMARAN Satyanarayanan2 \& WANG ZiJian, (2011). A gas chromatography/mass spectrometry method for the simultaneous analysis of 50 phenols in wastewater using deconvolution, Technology, 56: 275-284

22) F. Yang, Shen R, Long $Y$, Sun $X$, Tang F, Cai Q, Yao S., (2011). Magnetic microsphere confined ionic liquid as a novel sorbent for the determination of chlorophenols in environmental water samples by liquid chromatography. Environ. Monit. 13: 440-445.

23) L. Davidowski, (2011). the Determination of Minerals and Metals in Multi-Mineral/MultiVitamin Tablets by Flame Atomic Absorption Spectroscopy, Perkin Elmer, Inc. Shelton, CT 06484 USA Copyright @2011 
24) S. M. Abdel Azzem Abdel Salam, (2008). Preconcentration of some new modified sorbents for separation of some environmental pollutants, thesis for PhD Degre, Lecturer of Analytical Chemistry Faculty of Science, Fayoum University.

25) N. Zhang, Hanyong Peng, Bin Hu, (2012). Light-induced $\mathrm{pH}$ change and its application to solid phase extraction of trace heavy metals by high-magnetization $\quad \mathrm{Fe} 3 \mathrm{O} 4 @ \mathrm{SiO} 2 @ \mathrm{TiO} 2$ nanoparticles followed by inductively coupled plasma mass spectrometry detection, Talanta 6, TAL-12877.

26) S. Samad, Hassan Sereshti, Yaghoub Assadi, (2012). Ultra-preconcentration and determination of thirteen organophosphorus pesticides in water samples using solid-phase extraction followed by dispersive liquid-liquid microextraction and gas chromatography with flame photometric detection, Journal of Chromatography A, 1219: 61-65

27) F. Shakerian, Shayessteh Dadfarnia, Ali Mohammad Haji Shabani, (2012). Synthesis and application of nano-pore size ion imprinted polymer for solid phase extraction and determination of zinc in different matrices, Food Chemistry 134: 488-493

28) B. Dai, Meirong Cao, Guozhen Fang, Bing Liu, Xv Dong, Mingfei Pan, Shuo Wang, (2012). Schiff base-chitosan grafted multiwalled carbon nanotubes as a novel solid-phase extraction adsorbent for determination of heavy metal by ICP-MS, Journal of Hazardous Materials 8: ,HAZMAT-14127

29) A. Z. El-Sonbati, M.A. Diab, M.S. El-Shehawy, M. Moqba, (2010). Polymer complexes: XLX. Novel supramolecular coordination modes of structure and bonding in polymeric hydrazone sulphadrugs uranyl complexes, Spectrochimica Acta Part A 75: 394-405.

30) N. Burham, S.M. Abdel-Azeem , M.F. El-Shahat, (2006). Separation and determination of trace amounts of zinc, lead, cadmium and mercury in tap and Qaroun lake water using polyurethane foam functionalized with 4-hydroxytoluene and 4hydroxyacetophenone. Analytica Chimica Acta, 579: 193-201

31) S. G. Dmitrienko, O.A. Sviridova, S.B. Belousova, L.N. Pyatkova, A.Yu. Zolotav, (2000). Determination of nitrite ions using foam polyurethanes. Ind. Lab. 66: 80.

32) R. J. Cassella, V. A. Salim, L. S. Jesuíno, R. E. Santelli, S. L.C. Ferreira, M. S. de Carvalho, (2001). Flow injection determination of cobalt after its sorption onto polyurethane foam loaded with 2-(2-thiazolylazo)-p-cresol (TAC), Talanta 54: 61-67.

33) M. A. Chamjangali, S. T. Farooji, B. Bahramian, (2010). Application of chloromethylated polystyrene functionalized with $\mathrm{N}, \mathrm{N}-b i s(n a p h t h y l i d e n e i m i n o)$ diethylenetriamine in an on-line preconcentration system for the determin- ation of cadmium by FAAS, Journal of Hazardous Materials 174: 843-850

34) V. A. Lemos, S. L.C. Ferreira, (2001). On-line preconcentration system for lead determination in seafood samples by flame atomic absorption spectrometry using polyurethane foam loaded with 2-(2-benzothiazolylazo)-2-p-cresol,

Chimica Acta, 441: 281-289.

35) N. Burham, (2009). Separation and preconcentration system for lead and cadmium determination in natural samples using 2-aminoacetylthiophenol modified polyurethane foam, Desalination 249:1199-1205

36) S. G. Dmitrienk, O. A. sviridova, L. N. Pyatkova, V. M. Senyavin, (2002). polyurethane foam as solid chromogenic reagents for diffuse reflectance spectroscopy, Anal Bioanal chem. 374: 361-368

37) E. A. Moawed, M.F. El-Shahat, (2006). Preparation, characterization and application of polyurethane foam functionalized with a-naphthol for preconcentration and determination of trace amounts of nickel and copper in cast iron and granite, Reactive \& Functional Polymers. 66: 720-727.

38) M.F. El-Shahat, E.A. Moawed, A.B. Farag, (2007). Chemical enrichment and separation of uranyl ions in aqueous media using novel polyurethane foam chemically grafted with different basic dyestuff sorbents, Talanta 71: 236-241

39) N. Burham, S.M. Abdel-Azeem, M.F. El-Shahat, (2011). Determination of heavy metal ions in environmental samples employing preconcentration on novel resins of polyurethane foam linked with o-Aminophenol or o-Hydroxyphenylazonaphthol, International Journal of Environmental Analytical Chemistry, 91.

40) V. A. Lemos, L. N. Santos, M. A. Bezerra, (2010). Determination of cobalt and manganese in food seasonings by flame atomic absorption spectrometry after preconcentration with 2-hydroxyacetophenone-functionalized polyurethane foam. Journal of Food Composition and Analysis, 23: $277-281$

41) M. S. Sujamol, C. J. Athira, Y. Sindhu, K. Mohanan, (2010). Synthesis, spectroscopic characterization, electrochemical behavior and thermal decomposition studies of some transition metal complexes with an azo derivative, Spectrochimica Acta Part A 75: $106-112$

42) S. Rollas and Ş. G. Küçükgüzel, (2007). Biological Activities of Hydrazone Derivatives Molecules 12: 1910-1939

43) A. O. Alnajjar, M. E. El-Zariam, (2008). Synthesis and characterization of novel azo-morphine derivatives for possible use in abused drugs analysis, European Journal of Medicinal Chemistry, 43: 357-363

44) C. Manzur, M. Fuentealba, J. R. Hamon, D. Carrillo, (2010). Cationic organoiron mixed-sandwich hydraz- 
ine complexes: Reactivity toward aldehyde, ketones, diketones and dioxomolybdenum complexes, Coordination Chemistry Reviews. 254: 765-780

45) J. R. Memon, Saima Q. Memon, M.I. Bhanger, M.Y. Khuhawar, (2009). Use of modified sorbent for the separation and preconcentration of chromium species from industrial waste water Journal of Hazardous Materials. 16 (3): 511-516

46) S. L. C. Ferreira, J.B. de Andrade, M. Grac, A. Korna, M. G. Pereira, V. A. Lemosc, W. N.L. Santos, F. M.Rodrigues,d, A.S. Souza,H. S. Ferreira, E.G.P. Silva, (2007). Review of procedures involving separation and preconcentration for the determination of cadmium using spectrometric techniques, Journal of Hazardous Materials 145: 358-367

47) X. B. Patricia, Sergio. L. C. F., Leonardo S. G. T., (2009). Application of pyridylazo and thiazolylazo reagents in flow injection preconcentration systems for determination of metals, Talanta 79: 2-9

48) Y. Rena, X. Wei, M. Zhang, (2008). Adsorption character for removal $\mathrm{Cu}$ (II) by magnetic $\mathrm{Cu}$ (II) ion imprinted composite adsorbent, Journal of Hazardous Materials. 158: 14-22.

49) Lagergren S. (1898). Zur theorie der sogenannten adsorption geloster stoffe. Kungliga Svenska Vetenskapsakademiens. Handlingar 24: 1-39.

50) D. S. F. Gay, B. Royer, B. Martins, N. F. Cardoso, E. V. Benvenutti, T. M. H. Costa, E. C. Lima,
(2010). Silica grafted with a silsesquioxane containing the positively charged 1,4-diazoniabicyclo [2.2.2] octane group used as adsorbent for anionic dye removal, Desalination.

51) S. Sun, A. Wang, (2006). Adsorption kinetics of $\mathrm{Cu}$ (II) ions using N,O-carboxymethyl-chitosan, Journal of Hazardous Materials B131. 103-111.

52) L. V. A. Gurgel, J. C. P. de Melo, J. C. de Lena, L. F. Gil, (2009). Adsorption of chromium (VI) ion from aqueous solution by succinylated mercerized cellulose functionalized with quaternary ammonium groups, Bioresource Technology 100: 3214-3220

53) Z. Tu, Q. He, X. Chang, Z. Hu, R. Gao, L. Zhang, Z. Li, (2009). 1-(2-Formamidoethyl)-3-phenylurea functionalized activated carbon for selective solidphase extraction and preconcentration of metal ions, Analytica Chimica Acta 649: 252-257

54) M. F. El-Shahata, E.A. Moawedb, N. Burham, (2008). Preparation, characterization and applications of novel iminodiacetic polyurethane foam (IDAPUF) for determination and removal of some alkali metal ions from water, Journal of Hazardous Materials, 160: 629-633

55) B. Buke, U. Divrikli, M. Soylak and L. Elci, (2009). On-line preconcentration of copper as its pyrocatechol violet complex on chromosorb 105 for flame atomic absorption spectrometric determinations, Journal of Hazardous Materials. 163: 1298-1302. 